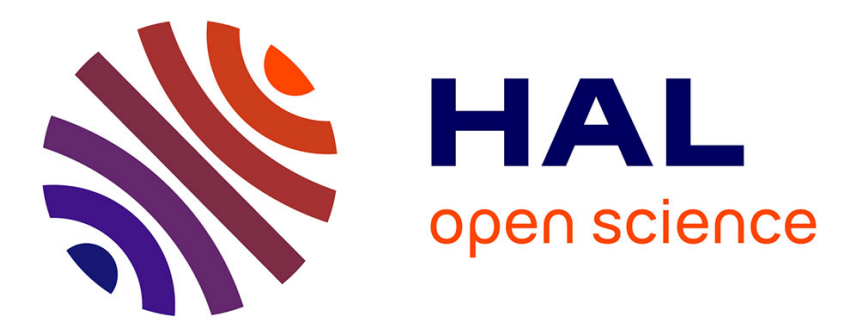

\title{
Mechanical activation of metallic powders and reactivity of activated nanocomposites: a molecular dynamics approach
}

Florence Baras, Quentin Bizot, Adrien Fourmont, Sophie Le Gallet, Olivier Politano

\section{To cite this version:}

Florence Baras, Quentin Bizot, Adrien Fourmont, Sophie Le Gallet, Olivier Politano. Mechanical activation of metallic powders and reactivity of activated nanocomposites: a molecular dynamics approach. Applied physics. A, Materials science \& processing, 2021, 127 (7), 10.1007/s00339-02104700-9 . hal-03357351

\section{HAL Id: hal-03357351 \\ https://hal.science/hal-03357351}

Submitted on 28 Sep 2021

HAL is a multi-disciplinary open access archive for the deposit and dissemination of scientific research documents, whether they are published or not. The documents may come from teaching and research institutions in France or abroad, or from public or private research centers.
L'archive ouverte pluridisciplinaire HAL, est destinée au dépôt et à la diffusion de documents scientifiques de niveau recherche, publiés ou non, émanant des établissements d'enseignement et de recherche français ou étrangers, des laboratoires publics ou privés. 


\title{
Mechanical Activation of Metallic Powders and Reactivity of Activated Nanocomposites: A Molecular Dynamics Approach
}

\author{
Florence Baras · Quentin Bizot • Adrien \\ Fourmont · Sophie Le Gallet · Olivier \\ Politano
}

Received: date / Accepted: date

\begin{abstract}
This work provides a description, at the atomic level, of a mechanical treatment on a mixture composed of two metallic powders. We used Molecular Dynamics to simulate the impact of grinding balls involving compaction and plastic deformation. Four binary mixtures were considered: Ni-Al, Ti-Al, Fe-Ni, and $\mathrm{Fe}-\mathrm{Cr}$, in order to assess the influence of the mechanical and structural properties of these pure elements on the characteristics of the activated mixture. The formation of nanometric mixing zones was tracked over deformation steps. The microstructure of the activated mixture was characterized using various indicators: local crystallographic configuration, radial distribution function, potential energy distribution, and mixing efficiency. The effects induced by the mechanical treatment were found to be specific for each binary system, and depended on both the mechanical and structural properties of the pure elements. Mechanical activation induces solid-state solubility, structural transformations, and defects. We also evaluated reactivity and transport properties at different temperatures in $\mathrm{Ni}-\mathrm{Al}$ and $\mathrm{Ti}-\mathrm{Al}$ nanocomposites fabricated by mechanical activation. We assessed the extent of their mixing zones, together with solubility, mobility, and the formation of intermetallics within these zones.
\end{abstract}

Keywords Powder metallurgy, High Energy Ball Milling, Metals and Alloys, Reactive nanocomposites, Molecular dynamics simulations

\section{Introduction}

Mechanical treatment of powders in planetary ball mills is a very common process used for several purposes including the synthesis of inorganic compounds and metallic nanocomposites, the formation of supersaturated solid solutions or metastable crystalline phases, and the elaboration of nanostructured materials or

Laboratoire Interdisciplinaire Carnot de Bourgogne, UMR 6303 CNRS-Université Bourgogne Franche-Comté, Dijon - France

E-mail: olivier.politano@u-bourgogne.fr 
amorphous alloys [1]. Mechanosynthesis, also termed mechanochemistry or mechanical alloying, supposes that the reaction is completed during the mechanical treatment [2]. In contrast, preliminary mechanical activation is used to fabricate reactive materials [3], and the reaction follows the activation process. As an example, the combination of mechanical activation and reactive sintering leads to the formation of nanostructured intermetallics [4], and nanostructured High Entropy Alloys [5]. Nanocomposites prepared by mechanical milling are also used in additive manufacturing [6,7], where attention is also paid to particle size and shape. Characterizing the reactive properties of activated powders is important to design reactive material with tailored reactivity, and to choose the most adequate parameters for the elaboration process (e.g., milling speed).

In practice, powders processed in planetary ball mills are submitted to a series of transformations induced by contact with grinding balls. The different elemental load modes observed in milling experiments include compression, shear, shock, cutting, and impact. Beinert et al. [8] classified the contacts between beads or bead and wall into four contact types: impact, torsion, shearing, and rolling, as a function of the relative velocity of colliding bodies. In addition, in situ observations have demonstrated that milling balls undergo complex motions in the jar [9]. Three milling regimes were identified as a function of milling parameters in the case of a large number of grinding balls [10]. In cascading regime, the balls are taken along the container and unroll upon each other from the bulk top to its base. Friction between grinding balls is dominant. In cataracting regime, the balls detach from the wall and impact the other balls or the opposite wall with high intensity. In centrifugal regime, the balls are stuck to the inner wall of the vial and move together with the vial. The specific milling regime was found to influence the microstructure and reactivity of the final powder mixture [11]. The action of balls on the blended elemental powders is essential to control the effects of milling. The two main activation factors are the collision of grinding balls with one another and with the milling wall, and friction between the grinding balls.

The fundamental question is to determine how the mechanical energy delivered by the mechanical process is stored in the powder, leading to enhanced reactivity in activated powders. The most common explanation is to assert that mechanical energy is stored in defects created during severe plastic deformation associated with mechanical treatment. According to Hoffman et al. [12], the defects due to mechanical treatment include: zero-dimensional point defects, such as vacancies; one-dimensional line defects, such as dislocations; two-dimensional area defects, such as stacking faults, grain boundaries, and contact areas with other phases. Three-dimensional volume defects include amorphous regions, pores, other phases, and metastable regions, corresponding to the development of structural transformations. The energy associated with different types of point defects, dislocations, and grain boundaries has been evaluated by Khina [13,14]. Low-dimensional defects appear to have a negligible effect on subsequent reactivity, in comparison with metastable phases, for which the formation mechanism is not yet understood.

In order to understand the effect of mechanical activation on reactivity, the $\mathrm{Ni}-\mathrm{Al}$ system has been widely studied experimentally. It has been shown that high-energy ball milling affects the reaction kinetics of $\mathrm{Ni} / \mathrm{Al}$ reactive composites $[15,16]$. Specifically, it was demonstrated that the effective activation energy of the reaction is significantly reduced after mechanical treatment [17]. This reduction may be attributed to structural refining that leads to an increase in the number of 
contact surfaces. In addition, microstructural analysis has shown that nanosized clusters are formed, which can serve as highly reactive precursors of new phases, and thus reduce the potential barrier to the initiation of exothermic reaction.

A problem of topical interest is to understand how impact and friction (the two prevalent actions during milling) act on the powder and modify microstructure evolution. Several studies have already been conducted at the atomic level. The plastic deformation induced by milling was modeled by cyclic deformation $[18,19]$. These studies have demonstrated that cyclic deformation forces chemical mixing due to dislocation gliding. The progressive amorphization and mixing of a binary system through extensive plastic straining has been studied in [20], by means of a strain-and-stack process similar to cold-rolling. Since the pioneering work of Holian and coworkers [21], the friction between sliding metallic blocks has been extensively studied (see for instance [22]). The frictional sliding of solid surfaces involves large plastic strains and strain gradients, high strain rates and strain rate gradients, and mechanical mixing from both contacting solids. Mechanical mixing was attributed to different mechanisms: interface instability that leads to local vorticity, dislocation and twin activity, and amorphization. Atomic mixing in metals under shear deformation has been studied at various interfaces in [23]. The mixing was found to be diffusive or "superdiffusive", depending on the coherence between interfaces. Heat dissipation due to sliding was investigated by means of non-equilibrium Molecular Dynamics simulations [24,25]. Atomic-scale mechanical mixing and generation of mixing layer were observed in the regions near the contact interface. The enhanced reactivity of mechanical activated systems has also been considered in the literature. The mechanisms of loading and chemical processes resulting from shock compaction have been investigated in the case of $\mathrm{Ni} / \mathrm{Al}$ composites by means of Molecular Dynamics simulations [26,27]. The role of porosities in such systems during deformation has been considered in [28]. The reactivity of $\mathrm{Ni}-\mathrm{Al}$ composites prepared by mechanical activation has been studied in order to detect the role played by the nanoscale mixing of the reagents [29]. But, in these studies, a nano-laminated structure or premixing of reagents was assumed. So a complete description of the effects induced by the mechanical treatment of elemental powders from activation to reaction is still lacking.

In the present work, we developed a set of Molecular Dynamics simulations mimicking the effects of grinding balls on powder particles, in order to obtain a better understanding of the mechanisms that take place during mechanical activation at the atomic level. We modeled the impact of grinding balls and their action on blended powders following Maurice and Courtney's idea [30]. Flat surface tools act on a large number of individual powder particles and cause uniaxial compression of the powder. Despite unavoidable limitations in system size and simulation time, large-scale Molecular Dynamics simulations are a useful tool to provide in situ observations during mechanical activation. We considered a set of metallic binary systems: $\mathrm{Ni}-\mathrm{Al}, \mathrm{Ti}-\mathrm{Al}, \mathrm{Fe}-\mathrm{Ni}$, and $\mathrm{Fe}-\mathrm{Cr}$. It is expected that a layered structure would be observed in ductile/ductile binaries. In the case of couples with dissimilar ductility, the resulting composite represents a metallic matrix with inclusions of the less ductile phase. The aim is to understand the specific behavior of each couple as a function of the mechanical and structural properties of its elemental constituents. Understanding the specific behavior of metallic couples during mechanical activation is important when this process is used to fabricate complex alloys. The efficiency of mechanically induced deformation will 
Table 1 EAM potential used for the different binaries.

\begin{tabular}{ll}
\hline Metallic binary system K-L & EAM potential \\
\hline Ni-Al & Purja Pun and Mishin (2009) [34] \\
Ti-Al & Zope and Mishin (2003) [35] \\
Fe-Ni & Bonny et al. (2009) [36] \\
Fe-Cr & Bonny et al. (2011) [37] \\
\hline
\end{tabular}

be investigated by measuring amorphization rate, chemical mixing efficiency, and the creation of defects. In order to evaluate their reactivity, activated $\mathrm{Ni}-\mathrm{Al}$ and Ti-Al systems were studied at different temperatures, below and above the melting point of the less refractory element $(\mathrm{Al})$. Both diffusion and reaction mechanisms were evaluated in $\mathrm{Ni}-\mathrm{Al}$ and $\mathrm{Ti}-\mathrm{Al}$ systems.

\section{Methods}

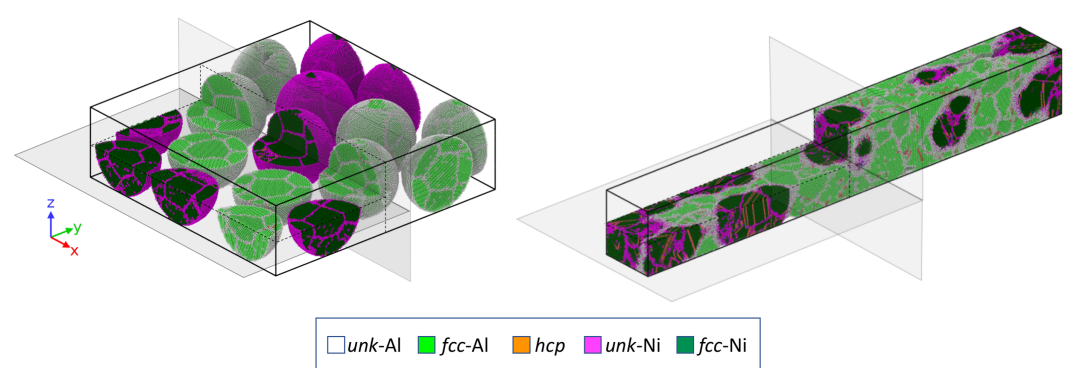

Fig. 1 Simulated system. Initial state with $f c c-\mathrm{Ni}$ and $f c c-\mathrm{Al}$ polycrystalline particles (left). System elongated along the $y$-direction after deformation (right).

All atomic simulations were performed with the Large-scale Atomic/Molecular Massively Parallel Simulator (LAMMPS) [31]. The LAMMPS is very well suited to study the properties of large-scale metallic systems by Molecular Dynamics and Embedded Atoms Method (EAM) potentials. The equations of motion of the atoms were integrated with a timestep of 1 fs. As shown in Fig. 1, we studied the mechanical deformation of a parallelepipedal simulation box filled with rounded particles ${ }^{1}$. The typical box size was $58.6 \mathrm{~nm}$ x $58.6 \mathrm{~nm} \times 16.8 \mathrm{~nm}$. To build this initial system, we randomly distributed 12 spheres of $16.6 \mathrm{~nm}$ diameter in the middle plane of the simulation box. Each sphere was filled with either a monocrystalline or polycrystalline metal. The polycrystalline systems were obtained by Voronoï tessellation $[32,33]$. The binary systems considered in the present study are listed in Table 1, with their corresponding EAM potentials. The number of atoms of each species and mole fraction are given in Table 2 . The properties of the elements are summarized in Table 3.

The system was first equilibrated at $300 \mathrm{~K}$ by a run of $50 \mathrm{ps}$ in the NVT (canonical) ensemble followed by $50 \mathrm{ps}$ in the NPT (isothermal-isobaric) ensemble.

\footnotetext{
1 Here, "particle" means powder particle
} 
Table 2 List of systems considered in the analysis. $N(K)$ is the number of atoms of element $K, N$ is the total number of atoms, $x=N(K) / N$ is the mole fraction.

\begin{tabular}{l|rr|r|r|r}
\hline$K-L$ & $N$ & $N(K)$ & $N(L)$ & $x($ at.\%) \\
\hline Ni-Al mono & 2106488 & 1097480 & 1009008 & 52 \\
Ni-Al poly & 2110942 & 1099995 & 1010947 & 52 \\
Ti-Al mono & 1510824 & 789312 & 721512 & 52 \\
Ti-Al poly & 1658148 & 866526 & 791622 & 52 \\
Fe-Ni mono & 2440686 & 1170390 & 1270296 & 48 \\
Fe-Cr mono & 2329662 & 1170390 & 1159272 & 50 \\
\hline
\end{tabular}

Table 3 Structural, thermodynamics and mechanical properties: Structure of pure elements at ambient temperature; Melting temperature $T_{m}$ of pure elements: Experimental value and theoretical value corresponding to the specific potential; Experimental value of the transition temperature $T_{\mathrm{tr}}$; Simulated tensile strength, $\sigma$; Experimental value of hardness, $H$.

\begin{tabular}{|c|c|c|c|c|c|c|}
\hline & structure & Exp. $T_{m}(\mathrm{~K})$ & Sim. $T_{m}(\mathrm{~K})$ & Exp. $T_{\operatorname{tr}}(\mathrm{K})$ & Sim. $\sigma(\mathrm{GPa})$ & Exp. $H(\mathrm{HV})$ \\
\hline$\overline{\mathrm{Al}}$ & fcc & 933 & $1055[34]$ & & $8.0[34]$ & 18 \\
\hline & & & $898^{a}-870^{b}[35]$ & & $6.6[35]$ & \\
\hline $\mathrm{Ni}$ & fcc & 1728 & $1710[34]$ & & $19.4[34]$ & 60 \\
\hline & & & & & $14.6[36]$ & \\
\hline $\mathrm{Fe}$ & $\mathrm{bcc} \rightarrow \mathrm{fcc}$ & 1811 & & 1185 & $\begin{array}{c}9.4[36] \\
9.4[37]\end{array}$ & 60 \\
\hline $\mathrm{Ti}$ & hcp $\rightarrow$ fcc & 1713 & $1571^{a}-1531^{b}[35]$ & 1155 & $14.8[35]$ & 99 \\
\hline $\mathrm{Cr}$ & bcc & 2180 & Not given & & $13.5[37]$ & 100 \\
\hline
\end{tabular}

${ }_{a}^{a}$ Melting temperature evaluated using the sphere method. ${ }^{b}$ Melting temperature evaluated using the two-phase method.

After this preliminary step, the atoms are integrated in the NPT ensemble. In order to mimic high-energy ball milling in which the average impact velocity of grinding balls is typically between 2 and $14 \mathrm{~m} / \mathrm{s}$, the box was shrunk at the constant velocity of $13.17 \mathrm{~m} / \mathrm{s}$, corresponding to a compression rate of $\epsilon=4.510^{10} \mathrm{~s}^{-1}$ along the $x$-direction [38]. The length of the simulation box was fixed along the $z$-direction, and adjusted along the $y$-direction by the Nose-Hoover barostat to maintain zero pressure in the system. The system deformation was monitored by computing the relative compression $\epsilon_{x x}=\left|\Delta L / L_{0}\right|=\left|\left(L-L_{0}\right) / L_{0}\right|$. In the following, we will use $\epsilon$ instead of $\epsilon_{x x}$, for simplicity. The system was deformed up to $80 \%$ of its initial length in $1.78 \mathrm{~ns}$ before studying its reactivity at a finite temperature. The reactivity simulations were carried out at constant temperature using the anisotropic NPT ensemble along all three directions.

The mechanical alloying observed during high-energy ball milling is necessarily related to the mechanical properties (e.g. Young's modulus, hardness, and tensile strength) of the elemental metal. Some of these properties can be evaluated by computing stress-strain curves. Nevertheless, hardness calculations will require nanoindentation simulations, which are complex and beyond the scope of this study. As a first approximation, stress-strain curves give a rough estimate of the hardness in a given binary by using an empirical linear dependance, $H \approx 3 \sigma$, reported between tensile strength and hardness [39]. The computed stress-strain curves are given in Supporting Information.

The atomic positions were visualized with the open-source software, OVITO [40]. The local environment (i.e. $f c c, b c c$, or unknown/amorphous) was determined for each atom, with the adaptative Common Neighbor Analysis (a-CNA) [41]. In 
the initial configuration depicted in Fig. 1, each atom was tagged with an indicator referencing its type and local structure.

\section{Results and Discussion}

3.1 Study of deformation

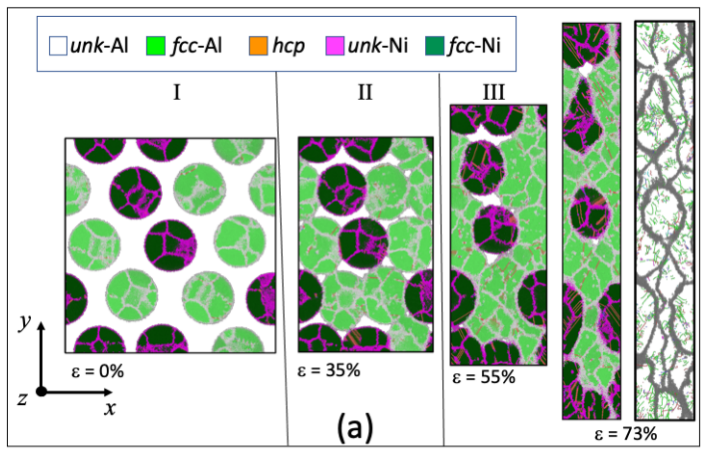

(a)

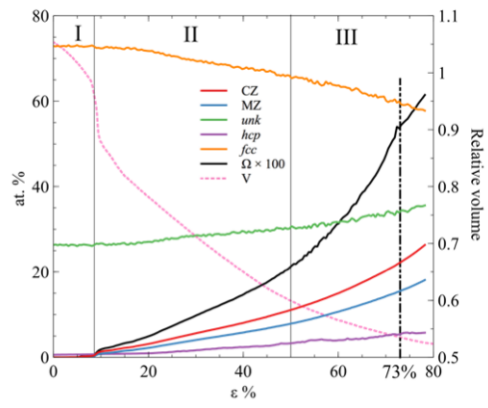

(b)

Fig. 2 Evolution of the Ni-Al system composed of polycrystalline spheres during deformation. (a) Snapshots at different deformation rates: $\epsilon=0 \%, \epsilon=35 \%, \epsilon=55 \%$ and $\epsilon=73 \%$ and DXA (Dislocation Extraction Algorithm) analysis at $\epsilon=73 \%$ [42] (b) Number of atoms (at.\%) in contact zones $\mathrm{CZ}$, in mixing zones MZ, and in local configuration $f c c, h c p$ or $u n k$ in the entire system as a function of deformation. Evolution of the mixing parameter $\Omega$ and of the relative volume of the simulation box. The relative volume is defined as the volume of the simulation box divided by $12 \times d^{3}$ with, $d$, the diameter of the particle.

We first describe the effect of deformation on the Ni-Al system. A progressive uniaxial compression was applied to the system of 12 polycrystalline particles of nickel and aluminum, as described in the previous Section. Figure 2a presents snapshots of the system in the $x-y$ plane at representative stages of the process. The simulation box shrank in the $x$-direction and elongated in the $y$-direction.

The particles were homogeneously distributed in the initial configuration. The compression applied to the simulation box induced modifications in the system as a function of deformation. Up $\epsilon=10 \%$, the particles moved freely, filling voids (stage I). At that deformation, the simulation box is equal to $12 \times V_{\text {cube }}$, where $V_{\text {cube }}$ is the volume of the cube in which a particle is inscribed. During compaction (stage II from $\epsilon=10 \%$ to $49 \%$ ), most of the empty space between particles was removed. At $\epsilon=35 \%, \mathrm{Al}$ particles seem to be crushed by Ni particles, and some dislocation started to develop in $\mathrm{Al}$ particles. Compaction was complete at $\epsilon=49 \%$ when the volume of the simulation box reached its inflection point. After compaction (stage III, $\epsilon>49 \%$ ), the powder was further compressed and underwent plastic deformation. The ductile $\mathrm{Al}$ particles deformed whereas $\mathrm{Ni}$ particles remained spherical. The microstructure of the composite formed after compression (Fig. 2a at $\epsilon=73 \%$ ) looks very similar to the samples obtained experimentally via HEBM [43], despite the difference in scale. 
In what follows, we analyze the different stages of the microstructural changes during deformation. To do so, several indicators were tracked, including the fraction of atoms in relation to their chemical identity, their local configuration ( $h c p$, $f c c, u n k$ ), and the particle it belonged to initially. Figure $2 \mathrm{~b}$ presents the evolution of the entire $\mathrm{Ni}-\mathrm{Al}$ system as a function of deformation in terms of these indicators. A major consequence of mechanical activation (MA) is the formation of contact zones between particles. In order to study this aspect, we defined two types of regions:

- Contact Zone (CZ): an atom in particle $a$ belongs to a CZ if one of its neighbors, in a sphere of radius $r_{\text {cut }}$, belongs to another particle b.

- Mixing Zone (MZ): an atom of type $i$ in particle $a$ belongs to an MZ if one of its neighbors, in a sphere of radius $r_{\text {cut }}$, belongs to another particle $b$ and is of type $j$, with $i \neq j$.

The choice of $r_{\text {cut }}=3.25 \AA$ is such that only nearest neighbors are selected. A group of atoms that will be in a particular region at the end of the deformation is noted "end-region". For instance, if we consider the group of atoms that will be in the $\mathrm{MZ}$ at the end (but not necessarily at any previous time except the end), the group is noted "end-MZ". Figure 3 highlights, in the initial system, the position of atoms that participate in end-CZs and end-MZ.

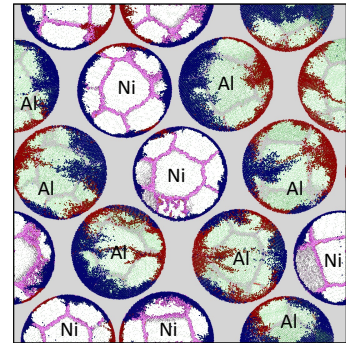

(a) Polycrystalline Ni-Al particles $\square$ unk-Al $\square f c c-\mathrm{Al} \square$ unk-Ni $\square f c c-\mathrm{Ni}$

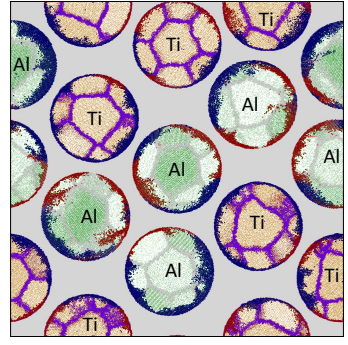

(b) Polycrystalline Ti-Al particles $\square$ unk-Al $\square f c c-A l ~ \square$ unk-Ti $\square h c p$-Ti

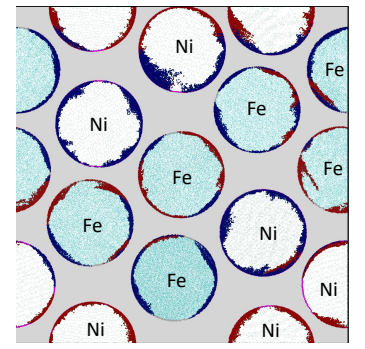

(c) Monocrystalline Fe-Ni particles $\square b c c-\mathrm{Fe} \square f c c-\mathrm{Ni}$

Fig. 3 Snapshots of the initial system prior to deformation $(x-z$ view). Atoms embedded in mixing zones after deformation are highlighted. Atoms in end-CZ are red and atoms in end-MZ are blue. (For interpretation of the references to color in this figure, the reader is referred to the online version of this article).

Table 4 gives the characteristics of all $K-L$ systems at $\epsilon=73 \%$ (where $K$ and $L$ stand for $\mathrm{Ti}, \mathrm{Al}, \mathrm{Fe}, \mathrm{Ni}, \mathrm{Cr})$ :

$-N_{\mathrm{MZ}}$ is the total number of atoms in MZs;

- $N_{\mathrm{MZ}}(K)$ is the number of atoms of species $K$ in MZs;

$-n_{\mathrm{MZ}}=N_{\mathrm{MZ}} / N$ is the fraction of atoms in MZs;

$-x_{\mathrm{MZ}}=N_{\mathrm{MZ}}(K) / N_{\mathrm{MZ}}$ is the mole fraction in mixing zones;

$-u_{\mathrm{MZ}}=N_{\mathrm{MZ}}(u n k) / N_{\mathrm{MZ}}$ is the fraction of unk-atoms in MZs;

- $\hat{u}_{\mathrm{MZ}}=N_{\mathrm{MZ}}(u n k-L) / N_{\mathrm{MZ}}(L)$ is the number of unk-atoms of species $L$ over the number of atoms of species $L$ in MZs.

In the case of the $\mathrm{Ni}-\mathrm{Al}$ polycrystalline system, the initial system already contained unk-atoms distributed at grain boundaries and on particle surfaces (see 
Table 4 System characteristics at deformation $\epsilon=73 \%$ for each binary K-L

\begin{tabular}{c|c|c|c|c|c|c}
\hline$\epsilon=73 \%$ & Ni-Al poly & Ni-Al mono & Ti-Al poly & Ti-Al mono & Fe-Ni mono & Fe-Cr mono \\
\hline \hline$n_{\mathrm{MZ}}$ (at.\%) & 15.2 & 12.6 & 10.2 & 7.6 & 4.5 & 4.7 \\
\hline$x_{\mathrm{MZ}}$ (at.\%) & 47.0 & 44.8 & 45.7 & 45.3 & 48.5 & 51.0 \\
\hline$u_{\mathrm{MZ}}$ (at.\%) & 74.4 & 69.3 & 52.9 & 45.6 & 62.5 & 31.8 \\
\hline$\hat{u}_{\mathrm{MZ}}$ (at.\%) & 88.6 & 86.3 & 60.4 & 54.7 & 54.2 & 23.3 \\
\hline$\Omega$ at $73 \%$ & 0.54 & 0.36 & 0.32 & 0.30 & 0.25 & 0.24 \\
\hline
\end{tabular}

Fig. 2a). During deformation, the number of $f c c$-atoms decreased in relation to unk-and hcp-atoms: unk-atoms were observed at contact zones and $h c p$-atoms in the dislocation network. The number of atoms in CZs and MZs increased during compaction (stage II). This rise was slightly more pronounced during plastic deformation (stage III). The number of atoms in CZs reached 20 at.\% in the final sample with more atoms in CZs than in MZs. This indicates that only a fraction of atoms in CZs will lead to effective chemical mixing. Most of the atoms in MZs are amorphous $\left(u_{\mathrm{MZ}}=74.4\right.$ at.\%), with a large majority of unk- $\mathrm{Al}\left(\hat{u}_{\mathrm{MZ}}=88\right.$ at.\%) (see Table 4$)$. The mole fraction in $\mathrm{MZ}\left(x_{\mathrm{MZ}}=47\right.$ at.\%) is not strictly preserved in comparison with the overall mole fraction $(x=52$ at.\%). This means that more $\mathrm{Al}$ atoms were trapped in the $\mathrm{MZ}$ during deformation. It appears that plastically deformable aluminum forms layers between Ni particles. Some Ni atoms were trapped in these amorphous Al layers. During compaction and compression of both $\mathrm{Al}$ and $\mathrm{Ni}$ particles, plastic deformation involved dislocations that can be quantified by the percentage of $h c p$-atoms in the system. As shown in Fig. 2a, plastic deformation is more noticeable in Ni particles, where the number of $h c p$ atoms is greater after deformation.

The atomic-level mixing induced by mechanical activation is best appreciated by considering a simple nondimensional order parameter. The short-range order parameter (SRO) is based upon nearest-neighbor atomic distribution:

$$
\Omega=\frac{\frac{c}{1-c} N_{i}^{j}+\frac{1-c}{c} N_{j}^{i}}{N_{i}^{j}+N_{j}^{i}}
$$

where $N_{i}^{j}$ is the average number of neighbors of type $j$ in a sphere of radius $r_{\text {cut }}=3.25 \AA$ around atoms of type $i$, and $c$ is the number density $(c=0.5$ in an equiatomic system). Values of $\Omega$ between 0 and 1 indicate partial chemical segregation, and $\Omega=1$ corresponds to a randomly mixed system. Thus $\Omega$ provides a sensitive measure of the state of chemical mixing in a given system [44]. Atoms located in end-MZs were identified, and the $\mathrm{SRO} \Omega$ was then evaluated for this specific group of atoms as a function of deformation. Note that atoms that do not belong to end-MZs contribute to $N_{i}^{j}$ if they are in the coordination sphere of radius $3.25 \AA$. The value of $\Omega$ at $\epsilon=73 \%$ is given in Table 4 . The evolution of $\Omega$ as a function of deformation is depicted in Fig. 2b. We observed that $\Omega$ increased with deformation but never reached the value corresponding to complete mixing.

We next considered the system of 12 polycrystalline particles of $\mathrm{Ti}$ and $\mathrm{Al}$. The $\mathrm{Ti}-\mathrm{Al}$ system behaves very differently from the $\mathrm{Ni}-\mathrm{Al}$ system. After deformation, the number of atoms in MZs $\left(n_{\mathrm{MZ}}\right)$ is lower: only 10 at.\% in the Ti-Al system compared to 15 at.\% in the $\mathrm{Ni}-\mathrm{Al}$ system. The nature of MZs is also different: only half of MZ-atoms are amorphous, with only a slight excess in $\mathrm{Al}$ atoms. In order 

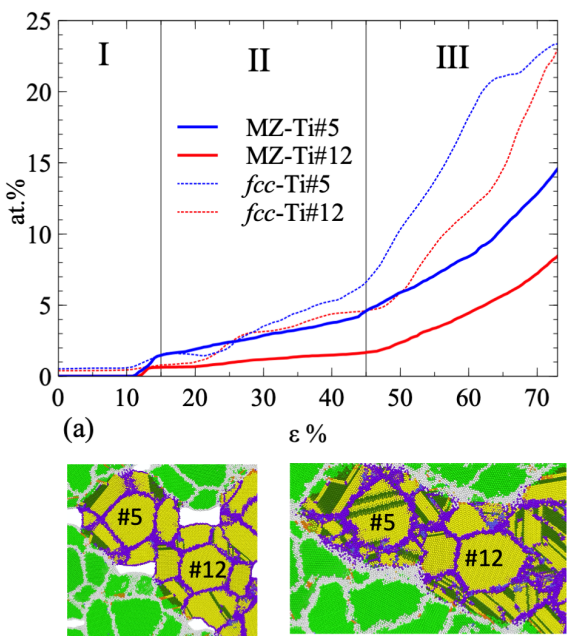

(b) $\varepsilon=40.7 \%$

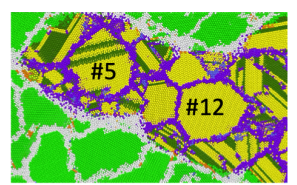

$\square$ unk-Al $\square$ fcc-Al $\square$ hcp-Al

unk-Ti $\square$ fcc-Ti $\square$ hcp-Ti

Fig. 4 Evolution of two Ti particles as a function of deformation. (a) Number of Ti atoms in particles \#5 and \#12 (at.\%) in MZs and number of fcc-Ti in particles \#5 and \#12 (at.\%). (b) Snapshot of Ti particles \#5 and \#12 at $\epsilon=40.7 \%$ during stage I (compaction) (c) Snapshot of Ti particles \#5 and \#12 at $\epsilon=60 \%$ during stage II (plastic deformation).

to visualize behavior during deformation, we considered two Ti particles (Fig. 4a). The relative number of Ti atoms in MZs increased with deformation but this evolution differs from one particle to another. As shown in Fig. 4b and 4c, particle $\# 5$ is surrounded by more $\mathrm{Al}$ particles than particle \#12. As a consequence, the number of atoms in MZs is greater for particle \#5. More Ti atoms were trapped in MZs during plastic deformation, with a substantial increase at $\epsilon=45 \%$ (close to the compaction limit, Fig. 4a). For the entire system, the SRO reaches 0.49 in MZs after deformation, corresponding to partial mixing between $\mathrm{Ti}$ and $\mathrm{Al}$.

Initially, Ti particles are in $h c p$ local configuration except in their external shell. During compaction, we observed that a non-negligible number of $h c p$-atoms became $f c c$, as depicted in Fig. 4a. This tendency is more pronounced during plastic deformation $(\epsilon>45 \%)$. The increase in $f c c$-Ti can be attributed either to the occurrence of stacking faults in Ti particles or to structural transformations. Indeed, the structural transformation $h c p \rightarrow f c c$ of Ti atoms has been observed in Ti-Al multilayers as a function of bilayer thickness and orientation at interfaces $[45,46]$. Nanometric Ti-Al multilayers can nevertheless be very stable in specific conditions: the interface between (002)-Ti plane and (111)-Al plane is very stable because of the slight misfit between the two structures [47]. In this case, the solubility of $\mathrm{Ti}$ in $\mathrm{Al}$ is very limited in the solid state. In the simulation of deformation, the random contact between $\mathrm{Ti}$ and $\mathrm{Al}$ particles generated interfaces with different orientations that may present weak stability. Deformation induces emergence of $f c c$-Ti inside Ti particles and promotes mixing between $\mathrm{Ti}$ and $\mathrm{Al}$ at low temperatures. 


\subsection{Microstructure after deformation}

We then studied the microstructure of the four binary systems Ni-Al, Ti-Al, Fe-Ni, and Fe-Cr after deformation using several indicators. Figure 5 shows the typical microstructure after deformation and the arrangement of atoms in MZs. The partial radial distribution functions $(\mathrm{RDF}), g_{K L}(r)$, are presented in Fig. 6. Partial RDFs, in comparison with the solid configuration of pure elements, provide the degree of amorphization, and the local rearrangement of atoms. Figure 7 gives the histogram of potential energy per atom in MZs in comparison with pure elements. It allows us to appreciate the effect of mechanical activation on atom stability. Finally, Fig. 3 allows us to detect where atoms in end-MZs and end-CZs were initially located: in the core, in the shell, or in internal grain boundaries. In what follows, we analyze the case of monocrystalline particles, with comparison in some cases to polycrystalline particles.
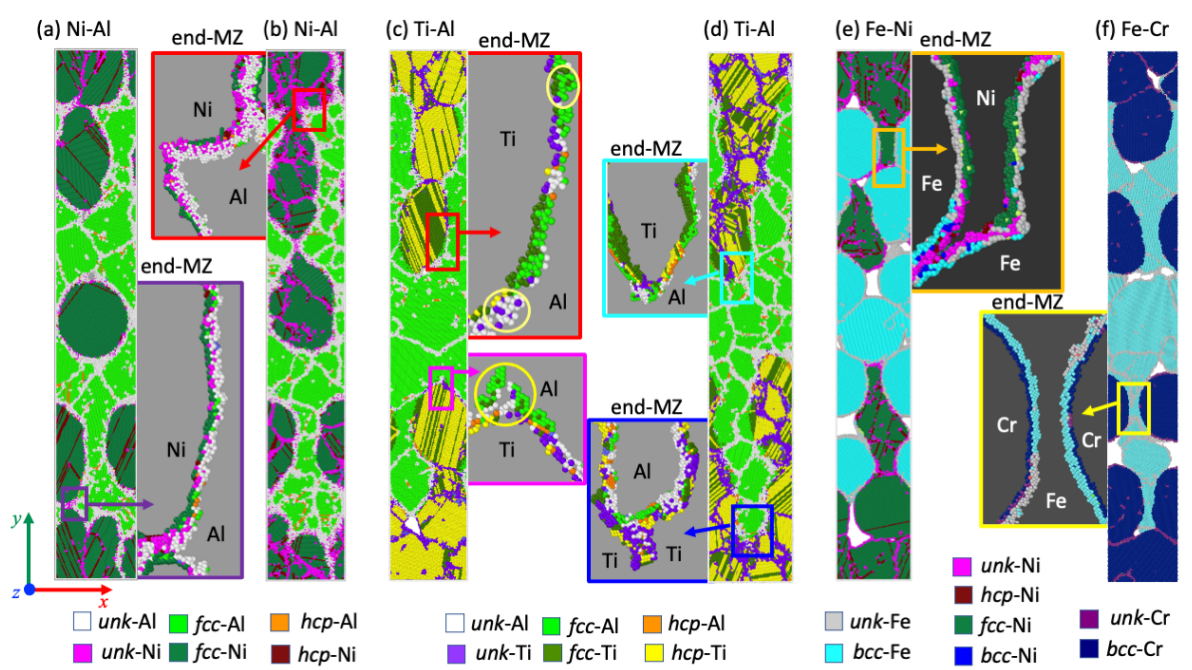

Fig. 5 Snapshots of a slice of $10 \AA$, around $z=100 \AA$ after deformation $(\epsilon=73 \%)$ : (a) Ni-Al monocrystalline particles (b) Ni-Al polycrystalline particles (c) Ti-Al monocrystalline particles (d) Ti-Al polycrystalline particles (e) Fe-Ni monocrystalline particles (f) Fe-Cr monocrystalline particles. Inserts represent enlarged views of mixing zones after deformation (MZs).

\subsubsection{Ni-Al system}

In the case of the $\mathrm{Ni}-\mathrm{Al}$ system, the mole fraction of $\mathrm{MZ}, x_{\mathrm{MZ}}$, is 45 at. $\%$ after deformation compared to the global mole fraction, $x, 52$ at.\%. This means that $\mathrm{MZs}$ trapped more $\mathrm{Al}$ atoms than $\mathrm{Ni}$ atoms during deformation. The majority of atoms in MZs are amorphous $\left(u_{\mathrm{MZ}}=70\right.$ at.\%) and most are $\mathrm{Al}$ atoms $\left(\hat{u}_{\mathrm{MZ}}=86\right.$ at.\%). In Fig. 6a, we observe that the partial RDF, $g_{\mathrm{AlAl}}(r)$ has the typical shape of an amorphous phase: the long-range order is lost. The first peak is shifted to the left in comparison with that of pure Al. The partial RDF $g_{\mathrm{NiNi}}(r)$ keeps the typical order of pure $f c c-\mathrm{Ni}$. At short range, the first nearest neighbors $\mathrm{Ni}-\mathrm{Al}$ are 

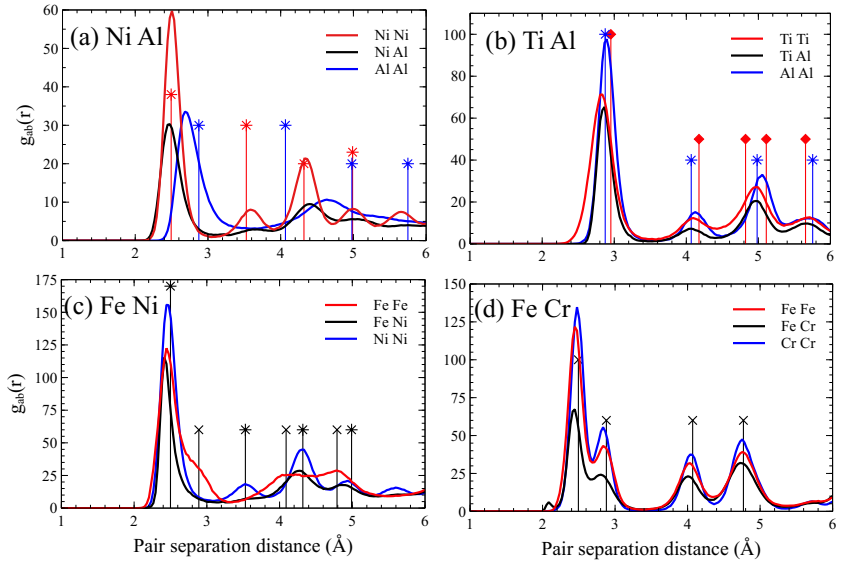

Fig. 6 Partial Radial Distribution Functions $g_{K L}(r)$ calculated in $e n d-\mathrm{MZs}$ at $\epsilon=73 \%$ for the four systems: (a) Ni-Al (b) Ti-Al (c) Fe-Ni and (d) Fe-Cr. Vertical lines indicate the position of nearest neighbors in pure systems: star for $f c c$, cross for $b c c$ and diamond for $h c p$ structures.

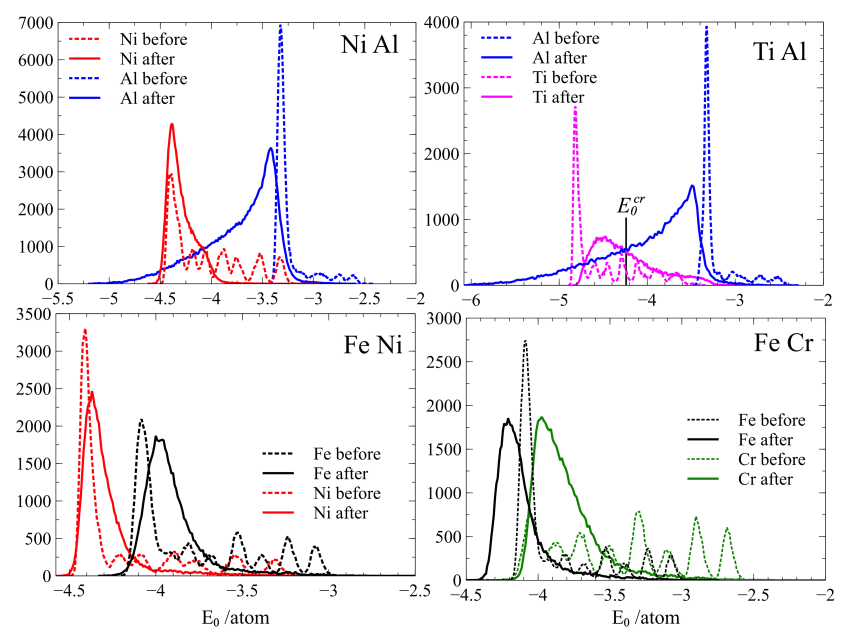

Fig. 7 Histogram of potential energy per atom prior to deformation and at $\epsilon=73 \%$ in end$\mathrm{MZs}$

located at the first peak of pure $f c c-\mathrm{Ni}$, but the second and subsequent neighbors indicate an amorphous phase. At short range, $f c c-\mathrm{Al}$ atoms are embedded in the $f c c$-Ni lattice.

The histogram of potential energy per atom provides supplementary information (Fig. 7a). Prior to deformation, Ni atoms in end-MZs are in a state corresponding to pure $\mathrm{Ni}$, but some are less stable, as indicated by multiple small peaks to the right of the main peak. These atoms are actually located in the shell of $\mathrm{Ni}$ particles. In contrast, a large number of $\mathrm{Al}$ atoms in end-MZs correspond to pure $\mathrm{Al}$. This result indicates that most of the $\mathrm{Al}$ in end-MZs are atoms that were initially located in the core of the particles, as shown in Fig. 3a. After de- 
formation, the distribution of potential energy per atom is quite different. The Al-distribution expands to lower energies with a maximum value slightly shifted compared to that of $\mathrm{Al}$ atoms prior to deformation. The Ni-distribution expands to the right, but the main peak remains unchanged. These typical profiles with overlap are associated with the amorphization of $\mathrm{Al}$, the partial dissolution of $\mathrm{Ni}$ into unk- $\mathrm{Al}$ atoms, and the substitution of $\mathrm{Al}$ atoms in the $f c c-\mathrm{Ni}$ lattice.

As shown in Fig. 5a (insert), a thin layer of $f c c-\mathrm{Ni}$ surrounds $\mathrm{Ni}$ particles in which a few $f c c-\mathrm{Al}$ atoms are trapped. The layers of amorphous $\mathrm{Al}$ atoms are located around $\mathrm{Al}$ particles and contain a few unk-Ni atoms. The same microstructure of MZs is observed after compression of $\mathrm{Ni}-\mathrm{Al}$ polycrystalline particles (see insert in Fig. 5b). The MZ is thicker in this case, with more dissolved unk-Al atoms and $u n k-\mathrm{Ni}$ atoms. This result indicates that internal grain boundaries in $\mathrm{Al}$ particles enhance the mobility of unk-Al during deformation. Indeed, the number of atoms in MZs is greater $\left(n_{\mathrm{MZ}}=15\right.$ at.\%) in the case of polycrystalline particles than in the case of monocrystalline particles $\left(n_{\mathrm{MZ}}=12.6\right.$ at.\%) (Table 4$)$. The presence of linear defects (lines of $h c p$-atoms) was observed in Ni monocrystalline particles (Fig. 5a), and in the inner grains of polycrystalline particles (Fig. 5b). Defects are fewer in $\mathrm{Al}$ particles. This must be related to the ductility of $\mathrm{Al}$ in comparison with that of $\mathrm{Ni}$.

\subsubsection{Ti-Al system}

The effect of deformation is noticeably different in the Ti-Al system. The layering of both elements is more pronounced. Here, the two elements have a different crystalline structure: $h c p$ - $\mathrm{Ti}$ and $f c c-\mathrm{Al}$, and the metallic radius of $\mathrm{Ti}$ is slightly larger than the metallic radius of $\mathrm{Al}: r_{\text {metal }}(\mathrm{Ti})=1.47 \mathrm{pm}$ and $r_{\text {metal }}(\mathrm{Al})=$ $1.43 \mathrm{pm}$. The number of atoms in MZs after deformation does not exceed 7.6 at.\% (Table 4). The mole fraction in MZs after deformation, $x_{\mathrm{MZ}}=45$ at. $\%$, corresponds to an excess of $\mathrm{Al}$ compared to the value prior to deformation, $x=52$ at.\%. Half of end-MZ atoms are amorphous, in equal ratios for $\mathrm{Al}$ and $\mathrm{Ti}$. Other atoms are either $f c c$ (32 at.\% in equal quantities for $\mathrm{Al}$ and $\mathrm{Ti}$ ) or $h c p$ (21 at.\% with an excess of $\mathrm{Ti}$ ).

Partial RDFs keep a long-range order typical of an ordered crystalline structure (Fig. 6b). The $g_{\text {TiTi }}(r)$ first peak shifts to a slightly lower value compared to the pure $h c p$-Ti first peak. The third and fourth peaks merge. The $g_{\text {AlAl }}(r)$ peaks are located at positions corresponding to $f c c$-Al. These observations corroborate the existence of an $f c c$ crystallographic structure in MZs after deformation. Histograms of potential energy per atom are plotted in Fig. 7b. The Al peak shifts to a lower value after deformation compared to the value prior to deformation. The $\mathrm{Al}$ distribution developed a long tail over a large range [-3.5 eV; $-6 \mathrm{eV}]$. The opposite result is observed in the Ti histogram. There is an overlap of energies for $\mathrm{Ti}$ and $\mathrm{Al}$ atoms. The crossing value $E_{0}^{\mathrm{cr}}$ of the two distributions corresponds to the energy value of $\mathrm{Al}$ atoms in direct contact with $\mathrm{Ti}$ atoms (or Ti with $\mathrm{Al}$ ). This value corresponds to the situation where half of the nearest neighbors of $\mathrm{Al}(\mathrm{Ti})$ are $\operatorname{Ti}(\mathrm{Al})$ atoms. Aluminum (Titanium) atoms with $E_{0}$ lower (higher) than $E_{0}^{\text {cr }}$ are surrounded by a larger number of atoms of the other species. Figure $3 \mathrm{~b}$ shows that a thick external shell of Ti particles contributes to CZs and MZs at the end of deformation, in comparison with the thin external shell for Ni particles in contact with Al (Fig. 3a). 
Figure $5 \mathrm{c}$ depicts the typical microstructure of mixing zones after deformation in the case of monocrystalline particles. We noted $f c c$-arrangement of $\mathrm{Ti}$ and $\mathrm{Al}$ atoms in small hexagons in (111) orientation (highlighted in the inserts). In Fig. $5 \mathrm{~d}$ (polycrystalline particles), we observed ordered regions with fcc-atoms in MZs after deformation. A substantial number of Ti atoms adopt $f c c$-configuration when in contact with $\mathrm{Al}$ atoms. In other regions, MZs are amorphous, with dispersion of $u n k-\mathrm{Ti}$ in a pool of unk-Al atoms. As in the case of the $\mathrm{Ni}-\mathrm{Al}$ system, polycrystalline particles promote the mixing of atoms during deformation because of the increasing mobility of unk-atoms in internal grain boundaries.

\subsection{3 $\mathrm{Fe}-\mathrm{Ni}$ system}

The effect of deformation was also analyzed in a system composed of monocrystalline $b c c-\mathrm{Fe}$ and $f c c-\mathrm{Ni}$. Both elements have comparable hardness. Figure $5 \mathrm{f}$ shows that Fe particles keep their rounded shape and Ni particles are crushed. The CZs and MZs are mainly fed with atoms from the thin shells of Fe particles and the thicker shells of Ni particles, as shown in Fig. 3c. We observed the creation of defects in $\mathrm{Ni}$ particles in the form of stacking faults and localized amorphization. The number of atoms in MZs is considerably reduced (4.5 at.\%) compared to that of systems with $\mathrm{Al}$, and the mole fraction in MZs is preserved. Amorphous atoms in MZs are in the majority $\left(u_{\mathrm{MZ}}=62.5\right.$ at.\%), with an excess of Fe. Crystallized atoms in MZs are either $f c c$-atoms (21 at.\%) or bcc-atoms (12 at.\%). Only a small proportion of crystallized atoms adopt the structure of the other element. The partial RDF $g_{\mathrm{FeFe}}(r)$ partly loses the strict $b c c$-structure, while $g_{N i N i}(r)$ keeps the long-range order (see Fig. 6c). The distributions of potential energy per atom developed a long tail for higher values of $E_{0}$ and their maximum shifted to the right (Fig. 7c). This result indicates a loss of stability for both elements. A typical MZ microstructure is presented in Fig. 5e. Typically, MZs are composed of $f c c-\mathrm{Ni} / u n k-\mathrm{Fe}$ or $b c c-\mathrm{Fe} / u n k-\mathrm{Ni}$ layers. A few atoms adopted the structure of the opposite element. In the case of the Fe-Ni system, deformation creates metastable mixing zones.

\subsubsection{Fe-Cr system}

Finally, we considered the effect of deformation in a system composed of monocrystalline $b c c-\mathrm{Fe}$ and $b c c-\mathrm{Cr}$. A snapshot of the system after deformation is given in Fig. 5f. Chromium hardness is much greater than that of iron. This may explain why Fe particles are crushed by $\mathrm{Cr}$ particles due to compression. The number of atoms in MZs is only 4.7 at.\%, with mole fraction $x_{\mathrm{MZ}}=51$ at.\%, almost equal to the mole fraction $x=50$ at.\%of the global system. The majority of atoms in MZs are in bcc-configuration (68 at.\%). This observation is corroborated by the analysis of partial RDFs (Fig. 6d). Both elements in MZs keep their bcc-ordered configuration. Peaks correspond to nearest neighbor positions of $b c c-\mathrm{Fe}$ and $b c c-\mathrm{Cr}$. Note that the lattice parameter of $b c c-\mathrm{Cr}$ is nearly equal to that of $b c c-\mathrm{Fe}$. The maximum of the histogram $E_{0}$ per atom of Fe shifts slightly to the left, and that of $\mathrm{Cr}$ to the right (Fig. 7d). Both distributions developed a long tail for higher values of $E_{0}$. Atoms in MZs are thus less stable compared to bulk atoms. As shown in Fig. $5 \mathrm{f}$ (insert), MZs contain layers composed of $b c c$-Fe and $b c c$-Cr or unk-Fe and $u n k$-Cr. Only a few localized defects were created, in the form of amorphous 
atoms in particle cores. In the case of the Fe-Cr system, deformation gives rise to thin metastable mixing zones, with an excess of bcc-atoms.

\subsection{Deformation and atom mobility}

We noted that the number of atoms in CZs and MZs increased during compaction (Fig. 2b). Particle motion is relatively complex, and several types of impact were observed. As an example, the collision between one Ni particle and one Al particle is depicted in Fig. 8. An impact occurs when particles have a relative velocity normal to the surface where the contact takes place (Fig. 8a). At impact, the two particles were in contact, and locally $\mathrm{Al}$ atoms became amorphous (Fig. 8b). The $\mathrm{Ni}$ particle started to rotate. This induced friction between the two particles. We observed that the $\mathrm{Ni}$ particle caught $\mathrm{Al}$ unk-atoms that remained stuck to the particle. At the same time, the Al was crushed and lost its rounded shape (Fig. $8 \mathrm{c}$ ). This sequence illustrates the very first steps of mechanical activation and the formation of mixing zones.

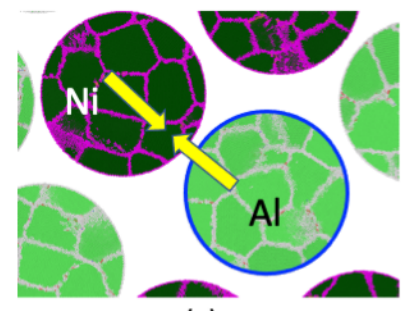

(a)

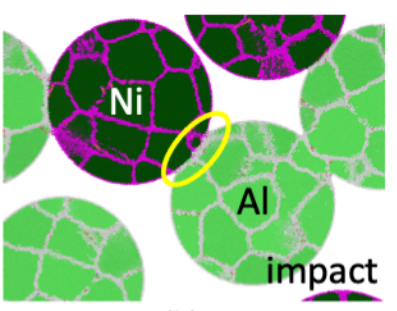

(b)

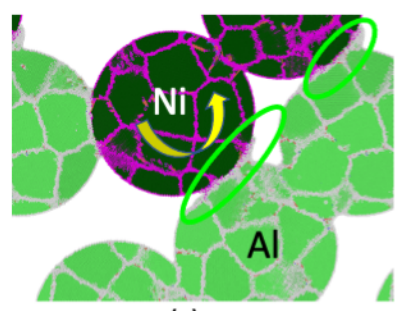

(c)

Fig. $8 \mathrm{Ni}-\mathrm{Al}$ system: (a) Collision between 2 particles. Arrows indicate the displacement direction. Blue circle marks the rounded shape of the Al particle prior to deformation. (b) Impact. The yellow ellipse indicates the contact zone. (c) Shearing between particles. The green ellipse indicates the contact zone. All atoms are represented with the color coding of Fig. 1.

Deformation induces a redistribution of atom positions in the system. Each particle has a distinct path during the simulation; hence it is necessary to analyze particles one by one and to take into account the displacement of the center of mass of each particle in order to study atomic mobility. In order to follow atoms during compression, we introduced an indicator to determine how atom mobility was affected. We here consider the relative displacement of atoms with respect to the particle they belong to, and define the Mean Square Displacement associated with mechanical deformation, $\mathrm{MSD}_{\text {deform }}$, as

$\operatorname{MSD}_{\text {deform }}=\frac{1}{N_{\text {part }}(K)} \sum_{j=1}^{N_{\text {part }}(K)} \frac{1}{N_{\text {end-MZ }}(K, j)} \sum_{i=1}^{N_{\text {end }-\mathrm{MZ}}(K, j)}\left|\vec{r}_{i}(t)-\vec{r}_{i}(0)-\left(\vec{r}_{\mathrm{CMj}}(t)-\vec{r}_{\mathrm{CMj}}(0)\right)\right|^{2}$

where $\epsilon=v t$ is deformation and $v$ the constant deformation rate, $K$ corresponds to one of the two elements in the system ( $\mathrm{Al}, \mathrm{Ni}, \mathrm{Ti}, \mathrm{Fe}$ or $\mathrm{Cr}), N_{\text {part }}(K)$ is the number of particles of the $K$ element, $\vec{r}_{i}(t)$ is the position of the $i$-th atom at time 
$t, \vec{r}_{\mathrm{CMj}}(t)$ is the center of mass position of the particle $j$, and $N_{\text {end-MZ }}(K, j)$ the number of atoms $K$ in end-MZs of particle $j$. The $\mathrm{MSD}_{\text {deform }}$ as a function of deformation is presented in Fig. 9a. The behavior is very different for each binary system:

- In the $\mathrm{Ni}-\mathrm{Al}$ system, $\mathrm{Al}$ is much more mobile than $\mathrm{Ni}$. This could be related to the higher ductility of $\mathrm{Al}$ compared to $\mathrm{Ni}$. In addition, the majority of $\mathrm{Al}$ atoms in MZs (86.3 at.\%) are amorphous (see Table 4), and amorphization promotes mobility. The Al mobility already starts at $\epsilon=20$ at.\% before plastic deformation. A possible mechanism is featured in Fig. 8, where amorphous $\mathrm{Al}$ atoms are stuck to the rotating Ni particle after impact.

- In the $\mathrm{Ti}-\mathrm{Al}$ system, $\mathrm{Al}$ is less mobile than in the $\mathrm{Ni}-\mathrm{Al}$ system. The mobility of both elements starts with plastic deformation. The interaction between $\mathrm{Ti}$ and $\mathrm{Al}$ is not strong enough to induce $\mathrm{Al}$ atoms to stick to Ti particles. The lower mobility of $\mathrm{Al}$ atoms is certainly due to the fact that half of the $\mathrm{Al}$ atoms in end-MZs are crystallized. The formation of $f c c$-seeds observed in MZs (Fig. $5 \mathrm{~d})$ restricts their mobility.

- In the Fe-Ni system, Fe and Ni are characterized by a similar hardness, and the number of $u n k-\mathrm{Ni}$ is just slightly larger than the number of unk-Fe. Nevertheless, Ni atoms are more mobile than Fe atoms. The main difference between the two elements is the large number of planar defects in $f c c-\mathrm{Ni}$ particles compared to $b c c$-Fe particles (Fig. 5e). Figure 3c confirms the fact that more Ni atoms located in the core of the particles participate in MZs with increased mobility.

- In the $\mathrm{Fe}-\mathrm{Cr}$ system, the hardness of $\mathrm{Cr}$ is greater than the hardness of Fe. This may explain the limited mobility of Cr atoms compared to Fe atoms. In addition, only 23 at.\% of $\mathrm{Cr}$ are amorphous in MZs. More unk-Fe atoms in MZs implies increased mobility.

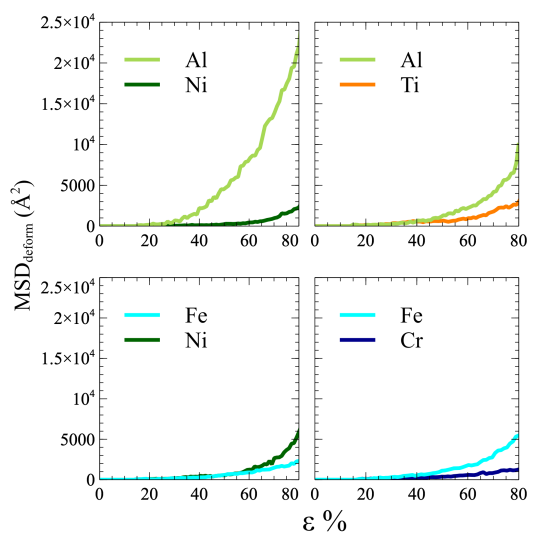

(a)

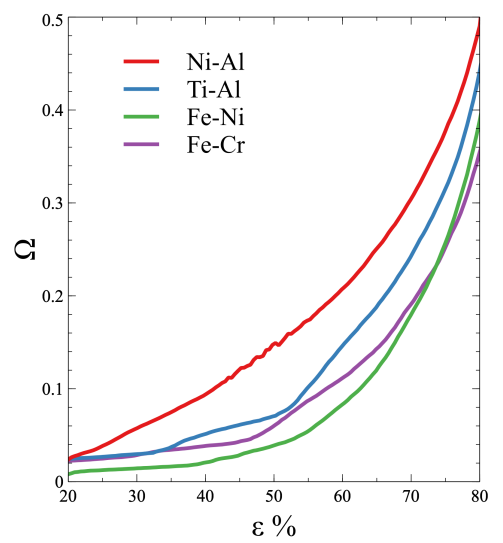

(b)

Fig. 9 Evolution of the $\mathrm{MSD}_{\text {deform }}$ (a) and mixing short-range order parameter $\Omega$ (b) among end-MZs during deformation for the four binary systems composed of monocrystalline particles. 
The short-range order parameter $\Omega$ (eq. (1)) as a function of deformation is depicted in Fig. 9. For all systems, we noted an acceleration of mixing during plastic deformation. Mixing efficiency correlates noticeably with atom mobility: $\Omega(\mathrm{Ni}-\mathrm{Al})$ is higher at any deformation rate. Mixing is more pronounced for populated MZs:

$$
n_{\mathrm{MZ}}(\mathrm{Ni}-\mathrm{Al})>n_{\mathrm{MZ}}(\mathrm{Ti}-\mathrm{Al})>n_{\mathrm{MZ}}(\mathrm{Fe}-\mathrm{Ni}) \sim n_{\mathrm{MZ}}(\mathrm{Fe}-\mathrm{Cr}) .
$$

But mixing is not directly related to the number of amorphous atoms in MZs:

$$
u_{\mathrm{MZ}}(\mathrm{Ni}-\mathrm{Al})>u_{\mathrm{MZ}}(\mathrm{Ti}-\mathrm{Al})>u_{\mathrm{MZ}}(\mathrm{Fe}-\mathrm{Ni})>u_{\mathrm{MZ}}(\mathrm{Fe}-\mathrm{Cr}) .
$$

As observed in the Ti-Al system, the formation of intermetallic seeds also leads to mixing.

The analysis of the four binaries demonstrates that the effect of deformation is directly related both to mechanical properties and structural characteristics (crystallographic structure, lattice parameters, etc.) of ground elements. Solidstate solubility associated with MZs, structural transformations, and defects were actually induced by the mechanical treatment.

\subsection{Reactivity and mobility in activated powders}

Two of the systems studied are reactive: Ti-Al and Ni-Al. Mechanical activation of elemental powders was found to increase their reactivity [3,29]. This result could be attributed to the formation of premixed nanoclusters, nano-sized precursors and/or defects, including amorphous and metastable regions. In order to understand the role of activation in reactivity, we studied the evolution of MZs in a temperature range close to ignition temperature, together with atom mobility in $\mathrm{MZs}$, and reactive mechanisms as a function of microstructure.

\subsubsection{Ti-Al system}

We first considered the Ti-Al activated system composed of polycrystalline particles after a deformation of $\epsilon=73 \%$. The system evolution was investigated at temperatures ranging from $850 \mathrm{~K}$ to $1150 \mathrm{~K}$, in $50 \mathrm{~K}$ steps. For this purpose, the system was heated up to the target temperature and simulations were carried out in the NPT ensemble. We focused on MZs because they reflect the reactivity between pure elements. The evolution of MZs as a function of time is represented in Fig. 10a. The number of atoms in MZs is 10 at.\% after deformation. At low $T$, in the range $(850 \mathrm{~K}-950 \mathrm{~K})$, the number of atoms in MZs reached a plateau value in $5 \mathrm{~ns}$. For larger $T$ values, the number of atoms in MZs continued to increase slowly over the time scale considered. Temperature was found to strongly influence the population in MZs. We must reach temperatures close to $1150 \mathrm{~K}$ for the whole system to be mixed. We next analyzed in detail the system at $T=850 \mathrm{~K}$, $950 \mathrm{~K}$, and $1100 \mathrm{~K}$, on each side of the melting temperature of the less refractory element $\left(T_{m}(\mathrm{Al})=870 \mathrm{~K}\right.$ for the Ti-Al EAM potential [35]). What is the reason for the increase in MZs? We expected partial or complete amorphization of $\mathrm{Al}$ and diffusion of $\mathrm{Ti}$ in $\mathrm{Al}$ atoms, resulting in an increase in the number of dissimilar close neighbors. 


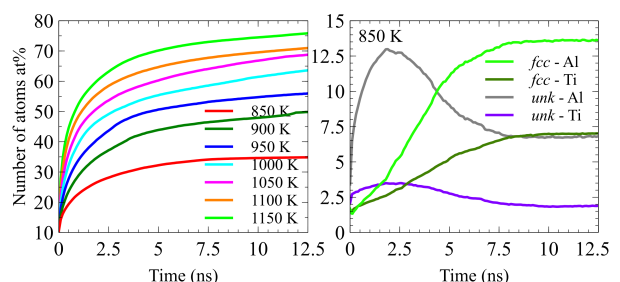

(a)

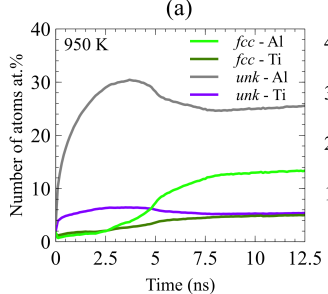

(c)

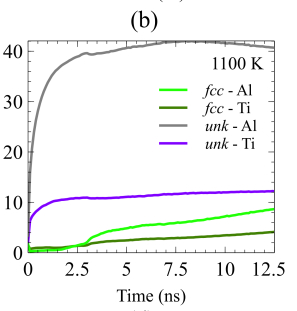

(d)

Fig. 10 (a) Evolution of the number of atoms (at.\%) in MZs as a function of time, for different temperatures. (b) Evolution of the number of $f c c$ - and unk-atoms (at.\%) in MZs at $T=850$ K. (c) $T=950 \mathrm{~K}$. (d) $T=1100 \mathrm{~K}$. The atomic percentage of atoms is relative to the number of atoms in the entire system.

At $T=950 \mathrm{~K}\left(T_{m}(\mathrm{Al})<T<T_{m}(\mathrm{Ti})\right)$ and $10 \mathrm{~ns}$, atoms in MZs represent more than half of the system $\left(n_{\mathrm{MZ}}=55\right.$ at.\%). Figure $10 \mathrm{c}$ shows the distribution of atoms according to their local configuration and type as a function of time. The number of unk-atoms sharply increased and reached a maximum at $4 \mathrm{~ns}$ with a majority of $\mathrm{Al}$ atoms. After that stage, $\mathrm{MZ}$ reorganization took place. Some amorphous atoms of $\mathrm{Ti}$ and $\mathrm{Al}$ progressively adopted an $f c c$-local configuration. The ratio between $f c c$ - $\mathrm{Ti}$ and $f c c-\mathrm{Al}$ in $\mathrm{MZ}, \xi_{f c c}=N_{f c c}(\mathrm{Ti}) /\left(N_{f c c}(\mathrm{Ti})+N_{f c c}(\mathrm{Al})\right)=$ 0.28 , is close to the typical value required for the formation of the $\mathrm{TiAl}_{3}$ intermetallic $\left(\xi_{f c c}=0.25\right)$. At $10 \mathrm{~ns}$ and later, a majority of atoms in MZs were amorphous $\left(u_{\mathrm{MZ}}=65\right.$ at.\%). We identified two transformations:

- melting of $\mathrm{Al}$ and partial dissolution of $\mathrm{Ti}$ in liquid

- formation of the intermetallic phase $\mathrm{TiAl}_{3}$. Note that the $\mathrm{D0}_{22}$ structure is based on a face-centered cubic structure.

$$
\mathrm{Al}_{\text {sol }}+\mathrm{Ti}_{\text {sol }} \rightarrow \mathrm{Al}_{\text {liq }}+(\mathrm{Al}+\mathrm{Ti})_{\text {sol }}+\mathrm{TiAl}_{3}
$$

A representative slice was chosen to analyze the local dynamics. Corresponding snapshots are given in Fig. 11. We identified the following characteristic behaviors at $950 \mathrm{~K}$ :

I After deformation, Ti particles are composed of $h c p-\mathrm{Ti}, f c c-\mathrm{Ti}$, and $u n k$-Ti at internal grain boundaries (GB). Defects in $h c p$-Ti grains are $f c c$-Ti linear defects (stacking faults). Aluminum particles lost their spherical shape and are composed of $f c c-\mathrm{Al}$ and $u n k-\mathrm{Al}$ in GBs. A few $h c p-\mathrm{Al}$ atoms correspond to defects in $\mathrm{Al}$ grains.

II As the system temperature was increased to $950 \mathrm{~K}$, we observed the rapid amorphization of Al surrounding Ti particles ( $0.2 \mathrm{~ns})$. Titanium atoms at the particle periphery started to dissolve. We noted that a small region of $f c c-\mathrm{Ti}$ promoted the formation of $f c c-\mathrm{Al}$ in its vicinity. 


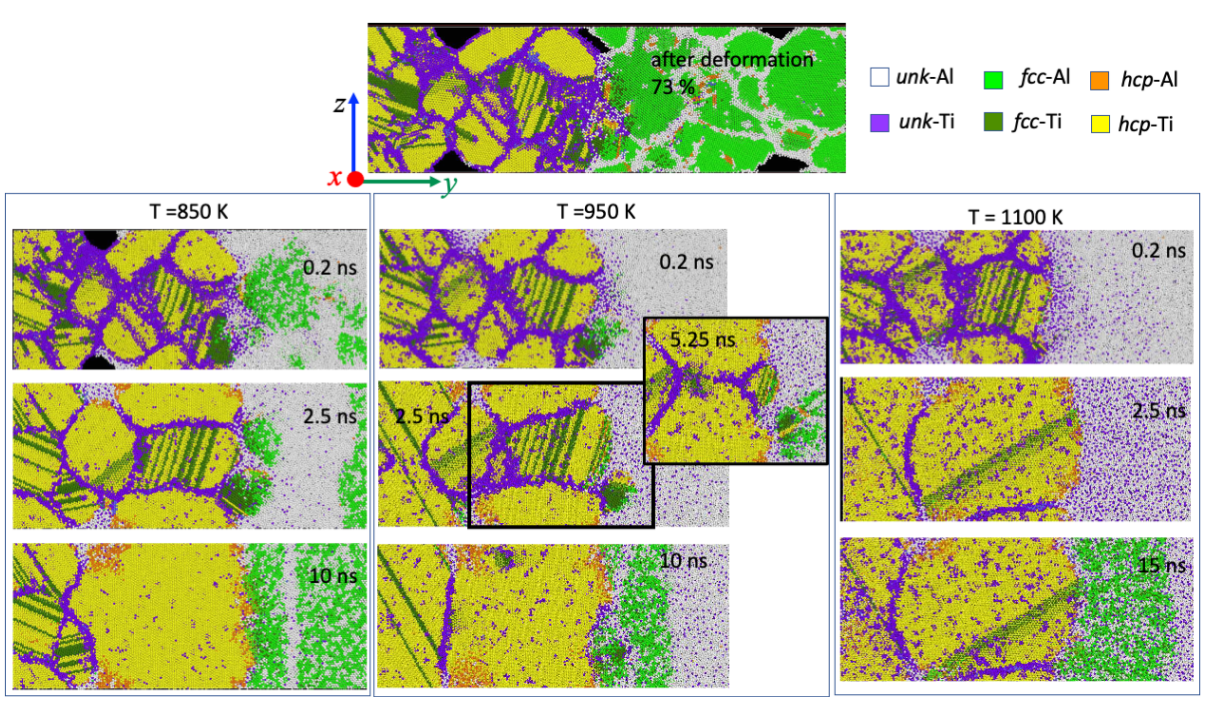

Fig. 11 Snapshots of a slice of $40 \mathrm{~nm}$ in the $y$-direction and $10 \mathrm{~nm}$ in the $x$-direction: system after deformation, system at $850 \mathrm{~K}, 950 \mathrm{~K}$, and $1100 \mathrm{~K}$, at different times.

III From $t=0.2 \mathrm{~ns}$ to $5.25 \mathrm{~ns}$, we observed a progressive coarsening of $h c p$-grains in $\mathrm{Ti}$ particles and disappearance of $f c c$-defects. Amorphous atoms in GBs either became $h c p$-atoms or dissolved in the surrounding liquid. After $5.25 \mathrm{~ns}$, the transformation of unk- $\mathrm{Al}$ to $f c c-\mathrm{Al}$ accelerated in $\mathrm{MZs}$.

IV At the end, Ti particles were surrounded by a few $h c p$-Al, a layer of $f c c$-atoms, and a liquid solution of $\mathrm{Ti}$ and $\mathrm{Al}$.

The final microstructure reflects the two processes described by (3).

We now analyze the behavior at $1100 \mathrm{~K}$. In less than $2.5 \mathrm{~ns}$, more than 50 at.\% are in MZs (Fig. 10a), with a majority of amorphous atoms (Fig. 10d). The snapshots in Fig. 11 ( $0.2 \mathrm{~ns}$ and $2.5 \mathrm{~ns})$ depict the rapid dissolution of $\mathrm{Ti}$ in the liquid and the reorganization of the Ti particles, with larger grains and reduction of fcc-defects. From 2.5 ns, the number of atoms in MZs further increased, reaching 70 at. $\%$ at $12.5 \mathrm{~ns}$ (Fig. 10a). In Fig. $10 \mathrm{~d}$, we noted that the number of $f c c-\mathrm{Al}$ increased continuously from $2.5 \mathrm{~ns}$ to $12.5 \mathrm{~ns}$, followed by a smooth increase in $f c c-\mathrm{Ti}$ atoms. The incoming atoms in MZs are $f c c$-atoms with a ratio $\xi_{f c c} \sim 0.33$ at 12.5 ns. A massive recrystallization of $\mathrm{TiAl}_{3}$ around the Ti particle took place at $15 \mathrm{~ns}$. At $1100 \mathrm{~K}$, reactive dissolution and formation of the intermetallic $\mathrm{TiAl}_{3}$ were both observed.

For the two temperatures above the melting point of $\mathrm{Al}$, we observed the spontaneous formation of the intermetallic phase $\mathrm{TiAl}_{3}$. The solubility of $\mathrm{Ti}$ in the solution, $x_{\mathrm{MZ}}=0.22-0.26$, is independent of temperature. At $850 \mathrm{~K}$, the situation is quite different. Because the temperature is below the melting point of $\mathrm{Al}$, we did not expect a global amorphization of $\mathrm{Al}$ atoms. A limited number of atoms $\left(n_{\mathrm{MZ}}=\right.$ 35 at.\%) were in MZs at $12.5 \mathrm{~ns}$ (Fig. 10a). This result indicates limited reactivity at that temperature. As shown in Fig. 10b, the number of unk-atoms increased, reaching a maximum at around $2 \mathrm{~ns}$. The decrease in unk-atoms was followed by an increase in $f c c$-atoms; the ratio is 0.22 in amorphous phase and 0.35 in $f c c$ phase. The microstructures depicted in Fig. 11 show a transient amorphization of 
$\mathrm{Al}$ atoms around $\mathrm{Ti}$ particles. At $2.5 \mathrm{~ns}$, Ti atoms were either dissolved in unk$\mathrm{Al}$ or substituted in the $f c c-\mathrm{Al}$ phase. At $10 \mathrm{~ns}$, the Ti particle mainly recovered its $h c p$-structure, with a thin layer of $h c p$-Al at the periphery. Aluminum $h c p$ atoms correspond to atoms that occupy vacancies liberated by outgoing $\mathrm{Ti}$ atoms. Dissolution operates as an exchange of $\mathrm{Ti}$ and $\mathrm{Al}$ atoms at interfaces. At the end, the particle was surrounded by an $f c c$ solid solution, an amorphous solution, and $f c c-A l$ with defects.

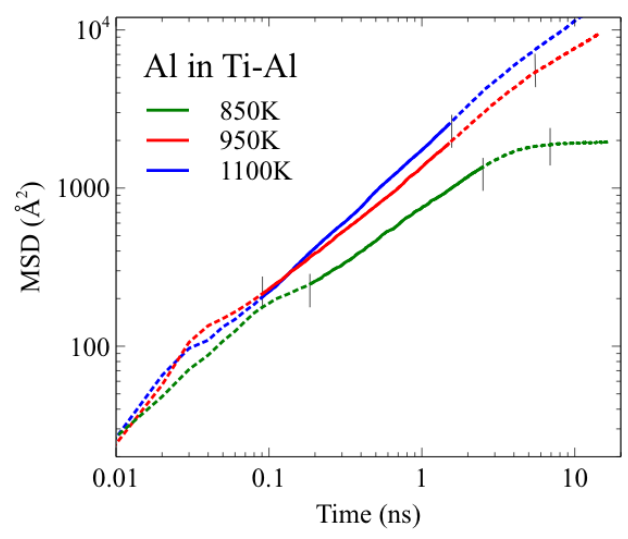

(a)

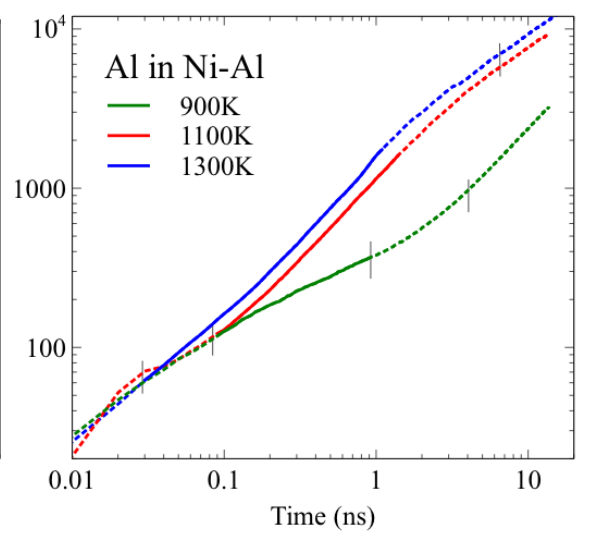

(b)

Fig. 12 MSD log-log plot for $\mathrm{Al}$ inside the $\mathrm{MZs}$ in the $\mathrm{Ti}-\mathrm{Al}$ system (a) and in the $\mathrm{Ni}-\mathrm{Al}$ system (b) at representative temperatures. Log-log plots for $\mathrm{Ti}$ in the $\mathrm{Ti}-\mathrm{Al}$ system and $\mathrm{Ni}$ in the $\mathrm{Ni}-\mathrm{Al}$ system are given in Supporting Information. Vertical lines delineate the 3 stages observed in the system evolution (see text). Solid line corresponds to the time interval over which diffusion coefficients are computed (see Table 5).

In order to study the mobility of atoms in MZs, we computed the mean square displacement (MSD) of atoms in MZs as a function of time:

$$
\mathrm{MSD}=\frac{1}{N_{\mathrm{MZ}}} \sum_{i=1}^{N_{\mathrm{MZ}}}\left|\vec{r}_{i}(t)-\vec{r}_{i}(0)\right|^{2}
$$

where $N_{\mathrm{MZ}}$ is the number of particles in the $\mathrm{MZ}, \vec{r}_{i}(0)$ is the reference position of the $i$-atom, $\vec{r}_{i}(t)$ is the atom position at time $t$. Note that the number of particles in MZs increases as a function of time. The MSD log-log plot at different temperatures is depicted in Fig. 12a. Typically, a diffusion mode corresponds to a linear dependance: MSD $\sim t$. Three characteristic slopes are observed in the MSD log-log plot that delineate three stages in the system evolution (the very beginning up to $0.1 \mathrm{~ns}$ corresponds to the suppression of voids between particles):

I First stage $(\sim 0.1 \mathrm{~ns}-\sim 2 \mathrm{~ns})$ : The MSD log-log plot is fitted by a straight line, characteristic of a diffusion regime in MZs composed of unk-atoms.

II Second stage (2 ns $-8 \mathrm{~ns})$ : There is a change of slope and curve bending. This reflects lower atom mobility associated with partial recrystallization in MZs.

III Third stage (after $8 \mathrm{~ns}$ ): There is another change of slope corresponding to a further slowing down of mobility. 
Table 5 Diffusion coefficients $\times 10^{-9}\left(\mathrm{~m}^{2} / \mathrm{s}\right)$ in $\mathrm{MZs}$ for the Ti-Al system and the $\mathrm{Ni}-\mathrm{Al}$ system. Values corresponding to temperatures above the melting point of $\mathrm{Al}$ are in bold.

\begin{tabular}{l|rrrrrrrrrr}
\hline $\mathrm{T}(\mathrm{K})$ & 700 & 800 & 850 & 900 & 950 & 1000 & 1050 & 1100 & 1150 & 1200 \\
\hline \hline $\mathrm{Al} / \mathrm{Ti}-\mathrm{Al}$ & & & 0.78 & $\mathbf{1 . 3 5}$ & $\mathbf{1 . 9 7}$ & $\mathbf{2 . 0 7}$ & $\mathbf{2 . 4 6}$ & $\mathbf{2 . 7 1}$ & $\mathbf{3 . 0 2}$ & \\
$\mathrm{Ti} / \mathrm{Ti}-\mathrm{Al}$ & & & 0.42 & $\mathbf{0 . 7 2}$ & $\mathbf{1 . 2 1}$ & $\mathbf{1 . 3 7}$ & $\mathbf{1 . 8 0}$ & $\mathbf{2 . 1 9}$ & $\mathbf{2 . 6 1}$ & \\
\hline $\mathrm{Al} / \mathrm{Ni}-\mathrm{Al}$ & 0.016 & 0.057 & & 0.38 & & 1.16 & & $\mathbf{1 . 9 0}$ & $\mathbf{2 . 2 6}$ \\
$\mathrm{Ni} / \mathrm{Ni}-\mathrm{Al}$ & 0.015 & 0.061 & & 0.45 & & 1.36 & & $\mathbf{2 . 2 9}$ & $\mathbf{3 . 0 5}$ \\
\hline
\end{tabular}

Table 6 Diffusion activation energy $(\mathrm{kJ} / \mathrm{mol})$ for the $\mathrm{Ti}-\mathrm{Al}$ system and the $\mathrm{Ni}-\mathrm{Al}$ system (eq. (5))

\begin{tabular}{l|cc|cc}
\hline & Al in Ti-Al & Ti in Ti-Al & Al in Ni-Al & 9 Ni in Ni-Al \\
\hline \hline$Q$ low $T$ & 69.84 & 69.45 & 100.54 & 103.95 \\
$Q$ high $T$ & 20.32 & 36.08 & 18.86 & 31.76 \\
\hline
\end{tabular}

Atom mobility can be directly related to the microstructure evolution of MZs depicted in Fig. 10b-d. The first stage corresponds to the increase in unk-atoms in MZs. In the second stage, the number of unk-atoms decreases in favor of $f c c$-atoms. In the third stage, the microstructure of MZs does not evolve significantly.

The diffusion coefficients are estimated for the time interval [0.1 ns - $3 \mathrm{~ns}]$ prior to recrystallization in MZs (Table 5). Figure 12 gives $\ln (D)$ for $\mathrm{Ti}$ and $\mathrm{Al}$ in $\mathrm{MZs}$ as a function of $1 / T$. We noted two slopes associated either with high temperatures $(950 \mathrm{~K}-1150 \mathrm{~K})$ or with low temperatures $(850 \mathrm{~K}-900 \mathrm{~K})$. The linear fit gives the corresponding activation energies $Q$ according to the Arrhenius law:

$$
D=D_{0} \exp \left(-\frac{Q}{R T}\right)
$$

where $D_{0}$ is the prefactor and $R$ the universal gas constant. The activation energies are given in Table 6 . Below the melting point of $\mathrm{Al}(850 \mathrm{~K})$, the diffusion coefficient is noticeably lower than at higher temperatures. The existence of two slopes observed in Fig. 13 reflects the change of microstructure in the MZs, with a transition from an amorphous system to pure liquid.

$\mathrm{T}(\mathrm{K})$

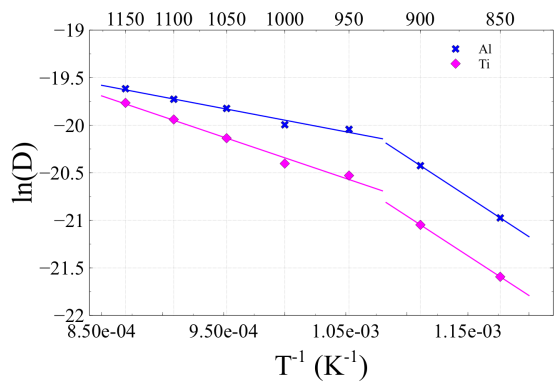

Fig. 13 Plot of $\ln (D)$ as a function of $1 / T$ for the Ti-Al system. 
For purposes of comparison, the diffusion coefficients were evaluated with Dictra (Thermo-Calc). The diffusion activation energy in pure liquid $\mathrm{Al}$ is $19 \mathrm{~kJ} / \mathrm{mol}$, close to the value measured in MD simulations. The diffusion coefficient of $\mathrm{Ti}$ in liquid $\mathrm{Al}$ at $1100 \mathrm{~K}$, with mole fraction $x(\mathrm{Ti})=0.2$, is $3.410^{-9} \mathrm{~m}^{2} / \mathrm{s}$, of the same order of magnitude as the value measured in MD simulations at high temperatures. Note, however, than this molar fraction is unrealistic in a system at equilibrium, due to the limited solubility of $\mathrm{Ti}$ in $\mathrm{Al}$ liquid.

In an activated system, Ti solubility in $\mathrm{Al}$ is greater than at equilibrium, which actually enhances reactivity. Figure 14 depicts the location of Ti atoms that will later be embedded in MZs. We identified Ti atoms in MZs at 2 ns (snapshot not shown), and reported their positions in black on a snapshot at 0.06 ns. Two locations were identified: internal grain boundaries and the external shell of the particle. Around the Ti particle, we observed a dissolution front in the liquid. Inside the Ti particle, GBs expanded with incoming $\mathrm{Al}$ and became channels for effective diffusion of $\mathrm{Ti}$ atoms toward the liquid solution. The GB expansion weakened particle stability so that it fragmented into small Ti-grains, which are more likely to dissolve. Both mechanisms promote the dissolution of Ti beyond the expected equilibrium value.

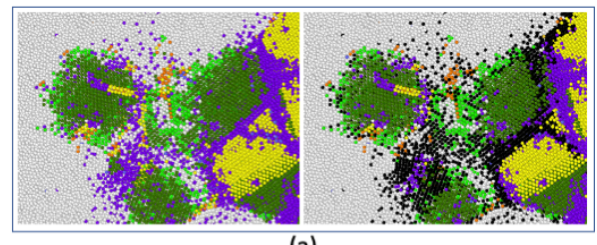

(a)

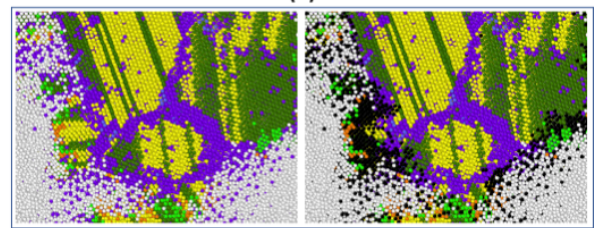

(b)

Fig. 14 Two detailed views of the snapshot after deformation (0.06 ns). Black atoms are Ti atoms in MZs at 2 ns. (a) Visualization of Ti atoms in grain boundaries (b) Visualization of $\mathrm{Ti}$ atoms in the external shell. Left: All atoms are represented with the color coding of Fig. 11. Right: Ti atoms in MZs at 2 ns are shown in black.

\subsubsection{Ni-Al system}

We next considered the Ni-Al activated system composed of polycrystalline particles after a deformation of $\epsilon=73 \%$. Mechanical treatment induces the formation of amorphous regions where atoms of $\mathrm{Ni}$ and $\mathrm{Al}$ are mixed, occupying 15 at.\% of the entire system. Mixing zones generally contain the same amount of $\mathrm{Ni}$ and $\mathrm{Al}$. In order to investigate the reactivity of the activated system, the system evolution was studied at temperatures ranging from $700 \mathrm{~K}$ to $1200 \mathrm{~K}$, in $100 \mathrm{~K}$ steps. For this purpose, the system was heated up to the target temperature, and simulations 


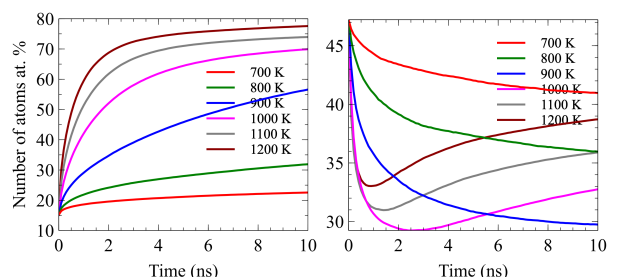

(a)

(b)

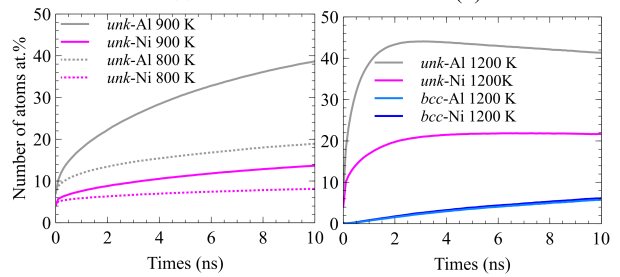

(c)

(d)

Fig. 15 (a) Evolution of the number of atoms (at.\%) in MZs as a function of time, for different temperatures. (b) Evolution of mole fraction $x_{\mathrm{MZ}}$ (at.\%) in MZs (c) Evolution of the number of unk-atoms (at.\%) in MZs at $T=800 \mathrm{~K}$ and $T=900 \mathrm{~K}$. (d) Evolution of the number of bcc- and unk-atoms (at.\%) in MZs at $T=1200 \mathrm{~K}$. The atomic percentage of atoms is relative to the number of atoms to the entire system.

were carried out in the NPT ensemble. The extent of MZs as a function of time is represented in Fig. 15a. The mole fraction $x_{\mathrm{MZ}}=N_{\mathrm{MZ}}(\mathrm{Ni}) / N_{\mathrm{MZ}}$ expressed in at.\% is given in Fig. 15b. The behavior depends on temperature:

- At low temperatures $(700 \mathrm{~K}$ and $800 \mathrm{~K})$, the number of atoms in MZs $\left(n_{\mathrm{MZ}}\right)$ remained limited and did not exceed 22 at.\% at $700 \mathrm{~K}$ and 30 at.\% at $800 \mathrm{~K}$. The proportion of $\mathrm{Ni}$ in MZs measured by $x_{\mathrm{MZ}}$ decreased as a function of time (Fig. 16b). This result indicates that more and more $\mathrm{Al}$ atoms are in MZs. If we compare the snapshot of the system prior to and after heating at $700 \mathrm{~K}$ (Fig. 16a and Fig. 16b), we note a coarsening of $\mathrm{Al}$ grains and the creation of amorphous regions around $\mathrm{Ni}$ grains with the mixing of $\mathrm{Ni}$ and $\mathrm{Al}$ atoms. As shown in Fig. 15c, MZs contained twice as much unk-Al as unk-Ni atoms.

- At an intermediate temperature $(900 \mathrm{~K}$, below the melting point of aluminum $T_{m}(\mathrm{Al})=1055 \mathrm{~K}$ for the Ni-Al EAM potential [34]), the number of atoms in MZs $\left(n_{\mathrm{MZ}}\right)$ grew continuously up to 56 at.\% at $10 \mathrm{~ns}$ because of the strong amorphization of $\mathrm{Al}$ atoms and subsequent dissolution of $\mathrm{Ni}$ in these amorphous regions. At $10 \mathrm{~ns}$ and beyond, the mole fraction $x_{\mathrm{MZ}}$ is stable and equal to 30 at.\%. Mixing zones almost completely replaced Al regions (Fig. 16c). Locally, seeds of $b c c$-atoms nucleated around $\mathrm{Ni}$ particles.

- The behavior of the number of atoms in MZs is more or less the same at high temperatures $(1000 \mathrm{~K}, 1100 \mathrm{~K}$, and $1200 \mathrm{~K})$. The number of atoms in MZs $\left(n_{\mathrm{MZ}}\right)$ increased before reaching a plateau value. At $1200 \mathrm{~K}$, almost 80 at. $\%$ of atoms are in MZs. As shown in Fig. 15b, the mole fraction $x_{\mathrm{MZ}}$ decreased abruptly before reaching a minimum. First, Al melted and then Ni atoms progressively dissolved in the liquid solution. Figure 15d shows the increase in the number of unk-Al followed by the increase in unk-Ni in less than 2 ns. After $2 \mathrm{~ns}$, the number of $b c c-\mathrm{Al}$ and $b c c-\mathrm{Ni}$ started to increase with the formation 
of intermetallic B2-NiAl. The number of unk-Al decreased slightly, while the number of unk-Ni remained constant. This result indicates that unk-Al atoms in MZs transformed into $b c c-\mathrm{Al}$, and that $u n k-\mathrm{Ni}$ atoms that became $b c c-\mathrm{Ni}$ were replaced in MZs by incoming $\mathrm{Ni}$ atoms that dissolved in the liquid region. At $10 \mathrm{~ns}$, the snapshot (Fig. 16d) depicts shrinking $f c c-\mathrm{Ni}$ particles surrounded by a liquid solution composed of $\mathrm{Ni}$ and $\mathrm{Al}$. Disoriented B2-NiAl grains surrounded the Ni particles and eventually formed a neck between particles. Grain boundaries progressively disappeared inside the Ni particles. We suppose that internal GBs acted as channels for outgoing unk-Ni that were dissolved in the melt. The mole fraction of $u n k-\mathrm{Ni}$ in MZs is 0.34 at $10 \mathrm{~ns}$, close to the expected equilibrium value.

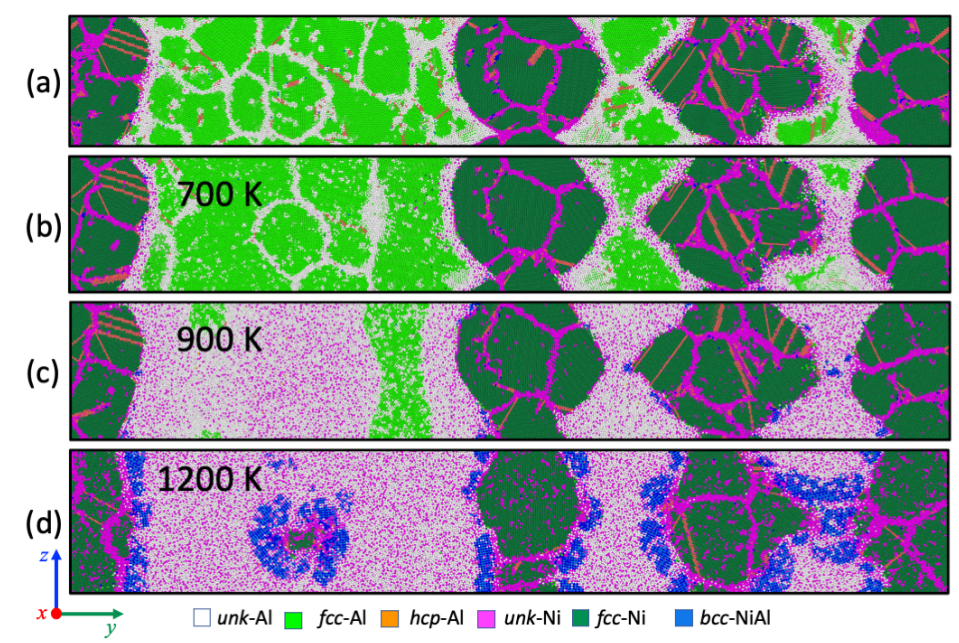

Fig. 16 Snapshots of the system (slice at $x=169 \mathrm{~nm}$ ) after deformation (a), at $700 \mathrm{~K}$ (b), $900 \mathrm{~K}(\mathrm{c})$, and $1200 \mathrm{~K}(\mathrm{~d})$ at $t=10 \mathrm{~ns}$.

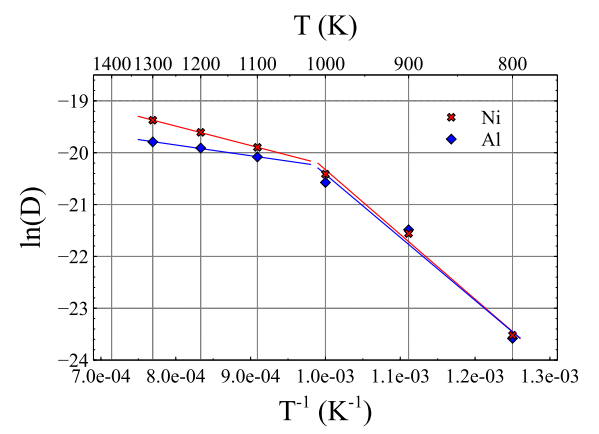

Fig. 17 Plot of $\ln (D)$ as a function of $1 / T$ for the Ni-Al system. 
The mobility of atoms in MZs was studied for the temperature range (700 K-1200 $\mathrm{K})$. The MSD log-log plot is presented in Fig. 12b. At high temperatures (1100 K and $1300 \mathrm{~K}$ ), we noted a diffusive regime followed by a slowing down of mobility, directly associated with the formation of the solid B2-NiAl intermetallic. By contrast, at $900 \mathrm{~K}$, the diffusive regime was followed by an increase in atom mobility. This behavior is actually associated with the polycrystallinity of $\mathrm{Al}$ particles: $\mathrm{Al}$ GBs played the role of diffusion paths and thus enhanced atom mobility.

Diffusion coefficients were evaluated in the time interval [0.1 ns - $1 \mathrm{~ns}]$ prior to recrystallization. Results are summarized in Table 5, Table 6, and Fig. 16. At high temperatures, above the melting point of $\mathrm{Al}$, the activation energy is close to 19 $\mathrm{kJ} / \mathrm{mol}$ for pure $\mathrm{Al}$ liquid, the value given by Dictra (Thermo-calc) $\left(D=6.9510^{-9}\right.$ $\mathrm{m}^{2} / \mathrm{s}$ at $\left.1100 \mathrm{~K}\right)$. In the case of a liquid solution $\mathrm{Ni}+\mathrm{Al}$ at $1100 \mathrm{~K}$, the diffusion coefficient of $\mathrm{Ni}$ in the solution given by Dictra ranges from $110^{-8} \mathrm{~m}^{2} / \mathrm{s}$ to $210^{-8}$ $\mathrm{m}^{2} / \mathrm{s}$, with the mole fraction $x(\mathrm{Ni})$ in the range $[0-0.3]$. In the MD simulations, the estimated diffusion coefficient is smaller by one order of magnitude. Note that the melting temperature given by the Purja and Mishin potential is $1050 \mathrm{~K}$, which is $170 \mathrm{~K}$ higher than the experimental value. This temperature difference will necessarily produce discrepancies when computing diffusivities close to the expected melting point. In addition, the discrepancy could be attributed either to the amorphous state of MZs, which occurs prior to complete melting in the time range over which the diffusion coefficient was estimated, or to the progressive dissolution of $\mathrm{Ni}$ into the liquid solution. At low temperatures, the diffusion coefficient measured in MZs is of the order of $10^{-11}-10^{-10} \mathrm{~m}^{2} / \mathrm{s}$, larger than the characteristic value in the $f c c$ solid phase $10^{-15}-10^{-13} \mathrm{~m}^{2} / \mathrm{s}$. This higher diffusivity results from the almost completely amorphous atomic arrangement of the Ni-Al MZs.

We observed three different behaviors as a function of temperature:

- At high temperatures (1000 K - $1200 \mathrm{~K})$, aluminum was completely melted. Large MZs with liquid solution $(\mathrm{Ni}+\mathrm{Al})_{\text {liq }}$ were formed. Note that, at $1000 \mathrm{~K}$, the system behaved as if it were above the melting point of $\mathrm{Al}$. The nanometric size of MZs induces their melting.

- At low temperatures ( $700 \mathrm{~K}$ - $800 \mathrm{~K}$ ), atoms diffused in the amorphous regions formed around $\mathrm{Ni}$ particles. In this case, MZs can be considered as an amorphous solid solution $(\mathrm{Ni}+\mathrm{Al})_{\text {sol }}$. Nevertheless, diffusion coefficients are larger than values characteristic of a solid but of the typical order of magnitude of diffusion in GBs.

- At $900 \mathrm{~K}$, below the melting point of aluminum, we noted an intermediate situation: extended amorphous regions in which Ni atoms diffuse more efficiently than at $800 \mathrm{~K}$ but less than in a liquid phase.

It appears that mechanical activation induced increased reactivity below the melting point of aluminum.

\section{Conclusions}

In the present work, Molecular Dynamics simulations were used to provide in situ observations of the mechanical activation of a pulverulent mixture composed of two metallic powders. A system composed of nanometric particles of $K$ and $L$ (Ni$\mathrm{Al}, \mathrm{Ti}-\mathrm{Al}, \mathrm{Fe}-\mathrm{Ni}$, and $\mathrm{Fe}-\mathrm{Cr}$ ) was subjected to compaction and plastic deformation 
mimicking the action of grinding balls during mechanical treatment. The system was then studied during deformation in order to detect the effect of mechanical activation. We focused on the 3D defects created by mechanical activation, in particular mixing zones (MZs) where the two elements are in direct contact. The efficiency of mixing, the degree of amorphization, and atom mobility were quantified during deformation. Mixing zones are of special interest because they could play the role of precursor in subsequent alloying processes. We observed that the effect of deformation depends both on mechanical properties and on the structural characteristics of $K$ and $L$. The main characteristics of mixing zones after deformation are summarized as follows:

- In the $\mathrm{Ni}-\mathrm{Al}$ system, both elements are $f c c$ but $\mathrm{Ni}$ is harder than $\mathrm{Al}\left(H_{\mathrm{Ni}}>\right.$ $\left.H_{\mathrm{Al}}\right)$. Mechanical treatment produces thick and amorphous MZs with an excess of Al. The other crystallized atoms adopt the $f c c-\mathrm{Ni}$ lattice. In this case, the ductile element adheres easily to hard particles, as in a wetting process. This is corroborated by the high mobility of $\mathrm{Al}$ atoms that already occurs during the compaction stage. After plastic deformation is completed, $h c p$ planar defects (stacking faults) are created in $\mathrm{Ni}$ particles.

- In the Ti-Al system, there is a considerable difference in hardness $\left(H_{\mathrm{Ti}} \gg H_{\mathrm{Al}}\right)$, as in the $\mathrm{Ni}-\mathrm{Al}$ system, but the elements have a different crystallographic structure $(h c p-f c c)$. The consequences of mechanical treatment are very different in comparison with the $\mathrm{Ni}-\mathrm{Al}$ system. Mixing zones have a limited extent, with only half of the atoms being amorphous, and a moderate excess of Al. Atom mobility is limited, and occurs during the plastic deformation stage. Crystallized atoms in MZs are $f c c-\mathrm{Al}, f c c-\mathrm{Ti}, h c p-\mathrm{Al}$, or $h c p$-Ti. In other words, $\mathrm{Al}(\mathrm{Ti})$ can adopt the original $\mathrm{Ti}(\mathrm{Al})$ structure. Aluminum atoms are stabilized when they are in close vicinity to Ti atoms. This feature leads to the creation of $f c c$ seeds that could play the role of nucleus in the formation of an intermetallic. After deformation, $f c c$ stacking faults (2D) and $f c c$ regions (3D) are created in Ti particles.

- In the Fe-Ni system, both elements have the same hardness $\left(H_{\mathrm{Fe}} \sim H_{\mathrm{Ni}}\right)$ but a different crystallographic structure $(b c c / f c c)$. After mechanical treatment, $\mathrm{Ni}$ particles are crushed by $\mathrm{Fe}$ particles that remain spherical. Thin mixing zones are formed with a majority of amorphous atoms and slightly more $\mathrm{Ni}$ unk-atoms. Crystallized atoms in MZs form layers of $f c c-\mathrm{Ni} / u n k$-Fe and unk$\mathrm{Ni} / b c c$-Fe. There is no mixing between $f c c$ and $b c c$ atoms. Stacking fault $(h c p)$ defects are created in $\mathrm{Ni}$ particles after deformation is completed.

- In the Fe-Cr system, both elements are bcc, with a difference in hardness $\left(H_{\mathrm{Cr}} \sim H_{\mathrm{Fe}}\right)$. Thin mixing zones with a low degree of amorphization are observed. Layers of $b c c-\mathrm{Fe} / b c c-\mathrm{Cr}$ and $u n k-\mathrm{Fe} / u n k-\mathrm{Cr}$ form the MZs. Amorphous defects are created in Fe particles.

Deformation due to mechanical activation leads to the formation of partly amorphous mixing zones. The nature and microstructure of MZs depend both on mechanical properties and on the microscopic characteristics of the pure elements.

The mechanical treatment produces $\mathrm{Ti}-\mathrm{Al}$ and $\mathrm{Ni}-\mathrm{Al}$ nanocomposites whose reactivity has been investigated in the present work. For this purpose, we focused on the evolution of mixing zones at different temperatures, just below and above the melting point $T_{m}(\mathrm{Al})$ of the less refractory element (here $\mathrm{Al}$ ). We also quantified 
the mobility in MZs by measuring the diffusion coefficients. The typical behavior can be summarized as follows:

- For the Ti-Al system, MZs increase during annealing. Annealing leads to the coarsening of $\mathrm{Ti}$ grains inside $\mathrm{Ti}$ particles, with suppression of defects and grain boundaries. For $T<T_{m}(\mathrm{Al})$, the reactivity is limited, with partial amorphization of $\mathrm{Al}$, formation of $f c c$ solid solution, and dissolution of $\mathrm{Ti}$ in amorphous Al. The diffusion coefficient prior to massive recrystallization corresponds to typical mobility in a dual-phase system: here, an amorphous phase. For $T \geq T_{m}(\mathrm{Al})$, the system is more reactive, with complete melting of $\mathrm{Al}$, dissolution of $\mathrm{Ti}$ into the liquid solution, and formation of the intermetallic $\mathrm{TiAl}_{3}$. The diffusion coefficient prior to crystallization corresponds to a melt. The mechanical treatment promotes the solubility of $\mathrm{Ti}$ in $\mathrm{Al}$ in comparison with equilibrium.

- For the Ni-Al system, annealing promotes broad MZs. The reactive behavior is directly related to the temperature. For $T<T_{m}(\mathrm{Al})$, the reactivity is limited. Mixing zones remain narrow, with the dissolution of $\mathrm{Ni}$ in the amorphous solid solution. The diffusion coefficient in MZs is of the same order of magnitude as diffusion in grain boundaries. For $T \sim T_{m}(\mathrm{Al})$, the reactivity is more pronounced, with broader MZs composed of unk-Al and $u n k-\mathrm{Ni}$. The diffusion coefficient in MZs remains smaller than in a liquid. For $T>T_{m}(\mathrm{Al})$, the activated system becomes very reactive, with the full amorphization of Al. Mixing zones extend over $\mathrm{Al}$ regions with effective dissolution of $\mathrm{Ni}$ into the liquid solution. The intermetallic B2-NiAl is formed around the solid Ni particles. The diffusion coefficient in MZs becomes close to that of a liquid.

Microscopic simulations provide an interesting tool to observe the effects of a mechanical treatment, and to study the reactivity of nanocomposites fabricated by a mechanical process. This work could be extended in order to take into account the activation associated with the friction of sliding interfaces. It would be interesting to estimate the efficiency of amorphization and chemical mixing, in the case where heat dissipation is taken into account. Another important issue is to understand the fragmentation process during HEBM. Alternative approach such as Extended Finite Element method [48] could be undertaken to handle fracture and crack propagation at the mesoscopic scale.

Acknowledgements The use of computational facilities at the Computing Center of the University of Bourgogne, PSIUN-CCUB, is gratefully acknowledged (Mesochallenge project). Part of this work was performed using HCP resources from GENCI-CINES (Grant2020A0090912032). This work has been supported by the EIPHI Graduate School (contract ANR17-EURE-0002). The authors thank Carmela Chateau-Smith for the careful reading of the manuscript.

\section{References}

1. C. Suryanarayana, Mechanical alloying and milling, Prog. Mater. Sci. 46, 1-184 (2001). doi:10.1016/S0079-6425(99)00010-9.

2. P. Balaz, M. Achimovicova, M. Balaz, P. Billik, Z. Cherkezova-Zheleva, J.M. Criado, et al., Hallmarks of mechanochemistry: from nanoparticles to technology, Chem. Soc. Rev. 42, 7571-7637 (2013). doi:10.1039/c3cs35468g 
3. A.S. Rogachev, Mechanical activation of heterogeneous exothermic reactions in powder mixtures, Russ. Chem. Rev. 88, 875-900 (2019). doi:10.1070/RCR4884

4. S. Paris, E. Gaffet, F Bernard, Z.A Munir, Spark plasma synthesis from mechanically activated powders: a versatile route for producing dense nanostructured iron aluminides, Scr. Mater. 50 691-696 (2004). doi: 10.1016/j.scriptamat.2003.11.019

5. A. Fourmont, S. Le Gallet, O. Politano, C. Desgranges, F. Baras, Effects of planetary ball milling on AlCoCrFeNi high entropy alloys prepared by Spark Plasma Sintering: Experiments and molecular dynamics study, J. Alloys Compd. 820, 153448 (2020). doi:10.1016/j.jallcom.2019.153448

6. A.A. Nepapushev, D.O. Moskovskikh, V.S. Buinevich, S.G. Vadchenko, A.S. Rogachev, Production of Rounded Reactive Composite Ti/Al Powders for Selective Laser Melting by High-Energy Ball Milling, Metall and Materi Trans B. 50, 1241-1247 (2019). doi:10.1007/s11663-019-01553-9

7. Q. Nguyen, C. Huang, M. Schoenitz, K.T. Sullivan, E.L. Dreizin, Nanocomposite thermite powders with improved flowability prepared by mechanical milling, Powder Technol. 327, 368-380 (2018). doi:10.1016/j.powtec.2017.12.082

8. S. Beinert, G. Fragnière, C. Schilde, A. Kwade, Analysis and modelling of bead contacts in wet-operating stirred media and planetary ball mills with CFD-DEM simulations, Chem. Eng. Sci. 134 648-662 (2015). doi:10.1016/j.ces.2015.05.063

9. S. Rosenkranz, S. Breitung-Faes, A. Kwade, Experimental investigations and modelling of the ball motion in planetary ball mills, Powder Technol. 212, 224-230 (2011). doi:10.1016/j.powtec.2011.05.021

10. C. F. Burmeister and A. Kwade, Process engineering with planetary ball mills, Chem. Soc. Rev. 42, 7660-7667 (2013). doi:10.1039/c3cs35455e

11. A.S. Rogachev, D.O. Moskovskikh, A.A. Nepapushev, T.A. Sviridova, S.G. Vadchenko, S.A. Rogachev, and A.S. Mukasyan, Experimental investigation of milling regimes in planetary ball mill and their influence on structure and reactivity of gasless powder exothermic mixtures, Powder Technol. 274, 44-52 (2015). doi:10.1016/j.powtec.2015.01.009

12. U. Hoffmann, C. Horst, E. Kunz, Reactive Comminution, in "Integrated Chemical Processes", K.Sundmacher, A. Keinle and A. Seidel-Morgenstern Eds., Wiley 407-436 (2005). doi: 10.1002/3527605738.ch14

13. B.B. Khina, Effect of mechanical activation on SHS: Physicochemical mechanism, Int. J Self-Propag. High-Temp. Synth. 17, 211- 217 (2008). doi: 10.3103/S1061386208040018

14. A.S. Mukasyan, B.B. Khina, R.V. Reeves and S.F. Son, Mechanical activation and gasless explosion: Nanostructural aspects, Chem. Eng. J. 174, 677-686 (2011). doi:10.1016/j.cej.2011.09.028

15. A.S. Rogachev, N.F. Shkodich, S.G. Vadchenko, F. Baras, R. Chassagnon, N.V. Sachkova, et al., Reactivity of mechanically activated powder blends: Role of micro and nano structures, Int. J Self-Propag. High-Temp. Synth. 22, 210-216 (2013). doi:10.3103/S1061386213040067

16. A.S. Rogachev, N.F. Shkodich, S.G. Vadchenko, F. Baras, D.Y. Kovalev, S. Rouvimov, A.A. Napapushev and A.S. Mukasyan, Influence of the high-energy ball milling on structure and reactivity of the $\mathrm{Ni}+\mathrm{Al}$ powder mixture, J Alloy Compd. 577, 600-605 (2013). doi:10.1016/j.jallcom.2013.06.114

17. C.E. Shuck, A.S. Mukasyan, Reactive Ni/Al Nanocomposites: Structural Characteristics and Activation Energy, J. Phys. Chem. A. 121, 1175-1181 (2017). doi:10.1021/acs.jpca.6b12314

18. S. Odunuga, Y. Li, P. Krasnochtchekov, P. Bellon, R.S. Averback, Forced Chemical Mixing in Alloys Driven by Plastic Deformation, Phys Rev Lett. 95, 045901 (2005). doi:10.1103/PhysRevLett.95.045901

19. F. Delogu, Forced chemical mixing in model immiscible systems under plastic deformation, J. Appl. Phys. 104, 073533 (2008). doi: 10.1063/1.2987476

20. A.C. Lund, C.A. Schuh, Molecular simulation of amorphization by mechanical alloying, Acta Mater. 52, 2123-2132 (2004). doi:10.1016/j.actamat.2004.01.004

21. J.E. Hammerberg, B.L. Holian and S.J. Zhou, Studies of sliding friction in compressed copper, Proceedings of the conference of the American Physical Society topical group on shock compression of condensed matter. AIP Conference Proceedings 370, 307-311 (1996). doi:10.1063/1.50796

22. D.A. Rigney, S. Karthikeyan, The Evolution of Tribomaterial During Sliding: A Brief Introduction, Tribol Lett. 39, 3-7 (2010). doi:10.1007/s11249-009-9498-3 
23. N.Q. Vo, J. Zhou, Y. Ashkenazy, D. Schwen, R.S. Averback, P. Bellon, Atomic Mixing in Metals Under Shear Deformation, Jom. 65 382-389 (2013). doi:10.1007/s11837-012-0542-7

24. E.-Q. Lin, L.-S. Niu, H.-J. Shi, Z. Duan, Molecular dynamics simulation of nano-scale interfacial friction characteristic for different tribopair systems, Appl Surf Sci. 258, 20222028 (2012). doi:10.1016/j.apsusc.2011.04.117

25. K. Chen, L. Wang, Y. Chen, Q. Wang, Molecular dynamics simulation of microstructure evolution and heat dissipation of nanoscale friction, International Journal of Heat and Mass Transfer. 109, 293-301 (2017). doi:10.1016/j.ijheatmasstransfer.2017.01.105

26. M.J. Cherukara, T.C. Germann, E.M. Kober, A. Strachan, Shock Loading of Granular $\mathrm{Ni} / \mathrm{Al}$ Composites. Part 1: Mechanics of Loading, J. Phys. Chem. C. 118, 26377-26386 (2014). doi:10.1021/jp507795w

27. M.J. Cherukara, T.C. Germann, E.M. Kober, A. Strachan, Shock Loading of Granular $\mathrm{Ni} / \mathrm{Al}$ Composites. Part 2: Shock-Induced Chemistry, J. Phys. Chem. C. 120, 6804-6813 (2016). doi:10.1021/acs.jpcc.5b11528

28. K.V. Manukyan, B.A. Mason, L.J. Groven, Y.-C. Lin, M. Cherukara, S.F. Son, A. Strachan and A.S. Mukasyan, Tailored Reactivity of $\mathrm{Ni}+\mathrm{Al}$ Nanocomposites: Microstructural Correlations, J. Phys. Chem. C. 116, 21027-21038 (2012). doi:10.1021/jp303407e

29. A. Fourmont, O. Politano, S. Le Gallet, C. Desgranges, and F. Baras, Reactivity of Ni-Al nanocomposites prepared by mechanical activation: A molecular dynamics study J. Appl. Phys. 129, 065301 (2021). doi: 10.1063/5.0037397

30. D.R. Maurice, T.H. Courtney, The physics of mechanical alloying: A first report, Metall. and Mat. Trans. A. 21, 289-303 (1990). doi:10.1007/BF02782409

31. S. Plimpton, Fast Parallel Algorithms for Short-Range Molecular Dynamics, J. Comp. Phys. 117, 1-19 (1995). doi:10.1006/jcph.1995.1039

32. A. Perron, S. Garruchet, O. Politano, G. Aral, V. Vignal, Oxydation of nanocrystalline aluminum by variable charge Molecular Dynamics, J. Phys. Chem. Solids. 71, 119-124 (2010). doi:10.1016/j.jpcs.2009.09.008

33. O. Politano, F. Baras, Reaction front propagation in nanocrystalline Ni/Al composites: A molecular dynamics study. J. App. Phys. 128, 215301 (2020). doi:10.1063/5.0028054

34. G.P. Purja Pun, and Y. Mishin, Development of an interatomic potential for the Ni-Al system, Philos. Mag. 89, 3245-3267 (2009). doi: 10.1080/14786430903258184

35. R.R. Zope, Y. Mishin, Interatomic potentials for atomistic simulations of the Ti-Al system, Phys. Rev. B 68, 024102 (2003). doi:10.1103/PhysRevB.68.024102

36. G. Bonny, R.C. Pasianot and L. Malerba, Fe-Ni many-body potential for metallurgical applications, Model. Simul. Mat. Sci. Eng. 17, 025010 (2009). doi: 10.1088/09650393/17/2/025010

37. G. Bonny, R.C. Pasianot, D. Terentyev, and L. Malerba, Iron chromium potential to model high-chromium ferritic alloys, Philos. Mag. 91, 1724-1746 (2011). doi: 10.1080/14786435.2010.545780

38. F. Delogu, G. Cocco, Numerical simulations of structural modifications at a Ni-Zr sliding interface, Phys. Rev. B. 72, 014124 (2005). doi:10.1103/PhysRevB.72.014124

39. P. Zhang, S.X. Li, Z.F. Zhang, General relationship between strength and hardness, Mat. Sci. Eng. A. 529, 62-73 (2011). doi:10.1016/j.msea.2011.08.061

40. A. Stukowski, Visualization and analysis of atomistic simulation data with OVITO the Open Visualization Tool, Modelling Simul. Mater. Sci. Eng. 18 , 015012 (2010). doi: 10.1088/0965-0393/18/1/015012

41. A. Stukowski, Structure identification methods for atomistic simulations of crystalline materials, Modelling Simul. Mater. Sci. Eng. 20, 045021-16 (2012). doi:10.1088/09650393/20/4/045021

42. A. Stukowski, Dislocation Analysis Tool for Atomistic Simulations. In: Andreoni W., Yip S. (eds) Handbook of Materials Modeling (Springer, Cham. 2018) doi: 10.1007/978-3-31944677-6_20

43. O. Politāno, A. Fourmont, S. Le Gallet, F. Baras, A. A. Nepapushev, A. S. Sedegov, S. G. Vadchenko and A. S. Rogachev, Mechanical activation of metallic powders in planetary ball mills: multi-scale modeling and experimental observation, IOP Conf. Ser.: Mater. Sci. Eng. 558, 012034 (2019). doi:10.1088/1757-899X/558/1/012034

44. A.C. Lund, C.A. Schuh, Topological and chemical arrangement of binary alloys during severe deformation, J. Appl. Phys. 95, 4815-4822 (2004). doi:10.1063/1.1691481

45. R. Banerjee, R. Ahuja and H.L. Fraser, Dimensionally Induced Structural transformations in Titanium-Aluminum Multilayers, Phys. Rev. Lett. 76, 3778 (1996). doi:10.1103/PhysRevLett.76.3778 
46. S.K. Maurya, J. F. Nie, A. Alankar, Atomistic analyses of HCP-FCC transformation and reorientation of $\mathrm{Ti}$ in Al-Ti multilayers, Comput. Mater. Sci. 192, 110329 (2021). doi: 10.1016/j.commatsci.2021.110329

47. Q. Bizot, O. Politano, A. A. Nepapushev, S. G. Vadchenko , A. S. Rogachev, and F. Baras, Reactivity of the Ti-Al system: Experimental study and molecular dynamics simulations, J. Appl. Phys. 127, 145304 (2020). doi: 10.1063/5.0004550

48. K.M. Hamdia and T. Rabczuk, Key Parameters for fracture toughness of particle/polymer nanocomposites; sensitivity analysis via XFEM modeling approach, In: Abdel Wahab M. (eds) Proceedings of the 7th International Conference on Fracture Fatigue and Wear. FFW 2018. Lecture Notes in Mechanical Engineering. Springer, Singapore, 41-51 (2019). doi: $10.1007 / 978-981-13-0411-8 \_4$ 